\title{
An Increase in Fat-Free Mass is Associated with Higher Appetite and Energy Intake in Older Adults: A Randomised Control Trial
}

\author{
Kelsie Olivia Johnson ${ }^{1,2, *(\mathbb{D})}$, Adrian Holliday ${ }^{1,3}$, Nathan Mistry ${ }^{1,4}{ }^{\mathbb{D}}$, Andrew Cunniffe ${ }^{1}$, Kieran Howard ${ }^{1}$, \\ Nicholas Stanger ${ }^{1}$, Lauren L. O’Mahoney ${ }^{1,5}\left(\mathbb{D}\right.$, Jamie Matu ${ }^{1,6}$ and Theocharis Ispoglou ${ }^{1}$ (D) \\ 1 Carnegie School of Sport, Leeds Beckett University, Leeds LS6 3QS, UK; \\ Adrian.holliday@newcastle.ac.uk (A.H.); n.mistry6@herts.ac.uk (N.M.); andycunniffe@live.com (A.C.); \\ kieran.howard@live.com (K.H.); N.Stanger@leedsbeckett.ac.uk (N.S.); llom1@leicester.ac.uk (L.L.O.); \\ J.Matu@leedsbeckett.ac.uk (J.M.); T.Ispoglou@leedsbeckett.ac.uk (T.I.) \\ 2 Higher Education Sport, Hartpury University, Hartpury GL19 3BE, UK \\ 3 Human Nutrition Research Centre, Population Health Sciences Institute, Newcastle University, \\ Newcastle NE1 7RU, UK \\ 4 School of Life and Medical Sciences, University of Hertfordshire, Hatfield AL10 9AB, UK \\ 5 Diabetes Research Centre, Leicester General Hospital, University of Leicester, Leicester LE5 4PW, UK \\ 6 School of Clinical \& Applied Sciences, Leeds Beckett University, Leeds LS1 3HE, UK \\ * Correspondence: kelsie.johnson@hartpury.ac.uk
}

\section{check for} updates

Citation: Johnson, K.O.; Holliday, A.; Mistry, N.; Cunniffe, A.; Howard, K.; Stanger, N.; O’Mahoney, L.L.; Matu, J.; Ispoglou, T. An Increase in Fat-Free Mass is Associated with Higher Appetite and Energy Intake in Older Adults: A Randomised Control Trial. Nutrients 2021, 13, 141. https:// doi.org/10.3390/nu13010141

Received: 14 November 2020 Accepted: 15 December 2020 Published: 1 January 2021

Publisher's Note: MDPI stays neutral with regard to jurisdictional clai$\mathrm{ms}$ in published maps and institutional affiliations.

Copyright: (C) 2021 by the authors. Licensee MDPI, Basel, Switzerland. This article is an open access article distributed under the terms and conditions of the Creative Commons Attribution (CC BY) license (https:// creativecommons.org/licenses/by/ $4.0 /)$.

\begin{abstract}
Cross-sectional studies in younger adults have demonstrated a positive association between energy intake (EI) and fat-free mass (FFM), with this relationship seemingly mediated by resting metabolic rate (RMR). Establishing a causal effect longitudinally would be prudent in older adults suffering from loss of appetite. We investigated the effects of FFM on RMR, appetite and EI in 39 healthy older adults (age: $66 \pm 4$ years, BMI: $25.1 \pm 3.5 \mathrm{~kg} \cdot \mathrm{m}^{2}$ ) assigned to either 12-week resistance training + protein supplementation group $(\mathrm{RT}+\mathrm{PRO})$ or control group $(\mathrm{CON})$. Body composition, subjective appetite, leptin, insulin, RMR and laboratory-measured ad libitum EI were measured at baseline, weeks 6 and 12 of the intervention, while daily EI at baseline and week 12 . FFM (+1.2 kg; $p=0.002)$, postprandial subjective appetite (+8 mm; $p=0.027)$, ad libitum EI (+119 kcal; $p=0.012)$ and daily EI (+133 kcal; $p=0.010)$ increased from baseline to week 12 in the RT + PRO. RMR, fasted subjective appetite, leptin and insulin concentrations remained unchanged (all $p>0.05)$. The increases ad libitum EI correlated with increases in FFM ( $\mathrm{r}=0.527, p=0.001)$, with $54 \%$ of the change in EI attributed to FFM changes. In conclusion, FFM increases were associated with an increased ad libitum EI and postprandial appetite in older adults.
\end{abstract}

Keywords: fat-free mass; ageing; older adults; appetite; energy intake; protein intake; resistance training

\section{Introduction}

Older adults typically experience reductions in energy intake (EI) as a result of an age-associated reduction in appetite-a phenomenon termed the "anorexia of ageing" [1]. The anorexia of ageing is the driver of unintentional weight loss, particularly to skeletal muscle tissue through protein malnutrition [2,3]. Energy intake declines at a greater rate than energy expenditure causing an imbalance in homeostatic appetite control and thus, body weight [4]. The appetite-regulatory system is complex and multifaceted [5]. We have recently conducted a meta-analysis which identified that concentrations of the anorexigenic hormone leptin, insulin, CCK, and PYY (postprandial only) were higher in older adults in comparison to younger adults [6]. This may partially explain reductions in hunger perceptions and EI in older adults.

Resting metabolic rate contributes $\sim 60-70 \%$ of total energy expenditure and decreases by $\sim 1-2 \%$ per decade in adults [7-10], which is aligned to the $1-2 \%$ reduction in muscle 
mass observed with ageing. In addition, resting metabolic rate has been strongly correlated with self-determined meal size, self-reported meal frequency and daily hunger across a 12 -week physical activity intervention in overweight/obese individuals [11,12]. Fat-free mass (FFM) is the greatest contributor to resting metabolic rate accounting for 60-70\% [7] and, research has demonstrated positive associations with self-selected meal size, ad libitum and total daily EI [13-16]. Indeed, path analysis has demonstrated that such associations between FFM and EI is mediated by resting metabolic rate; FFM and RMR together attributed to $62 \%$ of the variance in EI [17]. This suggests that FFM is the main determinant of resting metabolic rate and that metabolic requirements drive EI. It is proposed that the drive to eat may be underpinned by a protective mechanism to ensure that EI is not below energetic requirements $[18,19]$ and thus, it is likely that any increase in FFM would increase EI through the known associations between resting metabolic rate and EI shown by previous research $[11,13,14]$. However, these studies are correlational and observational thus, cause and effect cannot be established. Therefore, manipulating FFM to determine consequent changes in RMR, appetite and EI would be of interest, particularly for older adults given that both reduced appetite and FFM are observed with ageing.

Physical activity/exercise can raise energy expenditure several fold depending on the volume, mode and intensity; however, physical activity is not a potent nor stable driver of EI [20]. Evidence suggests that exercise-induced alterations in energy expenditure do not significantly influence EI in the immediate-post exercise period [21]. Additionally, any suppression in appetite through the phenomenon of exercise-induced anorexia is usually alleviated within $30 \mathrm{~min}$ after exercise cessation [22,23]. The same was demonstrated in unpublished data in our laboratory for older adults following resistance exercise (RE), whereby appetite and EI were unaffected in the two-hour post-exercise period compared to the non-exercising control group. However, exercise conducted over an extended period from 9-16 days have unveiled partial compensatory responses [24,25]. These changes have also been observed in appetite-related hormone concentrations under conditions of weight loss [26]. The compensatory responses are consistent with the proposition that energy expenditure acts as a driver for EI. However, the association between exercise and EI is weaker than the relationship of resting metabolic rate with EI, likely due to resting metabolic rate providing a greater contribution to total energy expenditure [19].

Currently, no research to date has manipulated body composition, in particular, FFM experimentally to determine the effects on resting metabolic rate and thus appetite and EI longitudinally. Therefore, the purpose of this study was to promote gains in muscle massthrough the established approach of resistance training and protein supplementation $[27,28]$ to manipulate FFM and determine the longitudinal responses in RMR, appetite and EI in older adults prone to reductions in muscle mass and anorexia of ageing.

\section{Materials and Methods}

\subsection{Participants}

Forty-six participants were initially enrolled on to the study after initial screening. Following withdrawals (see Figure 1) 39 healthy, independently living older adults (22F, 17M; Table 1) were included in the study. Participants were recruited if they met the following inclusion criteria: Aged 60 years or over, do not smoke, no history of cardiovascular disease, metabolic disease or dyslipidaemia, not dieting within the last 3 months, not taking drugs known to affect digestion or metabolism, participated in at least "some activity" according to physical activity classification domains, weight stable for the last 3 months, i.e., $<2.3 \mathrm{~kg}$ change in body weight [29], tolerance and no allergies for food items and ingredients provided during the experimental trials and not currently following a structured resistance training programme or have recently participated in structured resistance exercise within the past 12 months. 


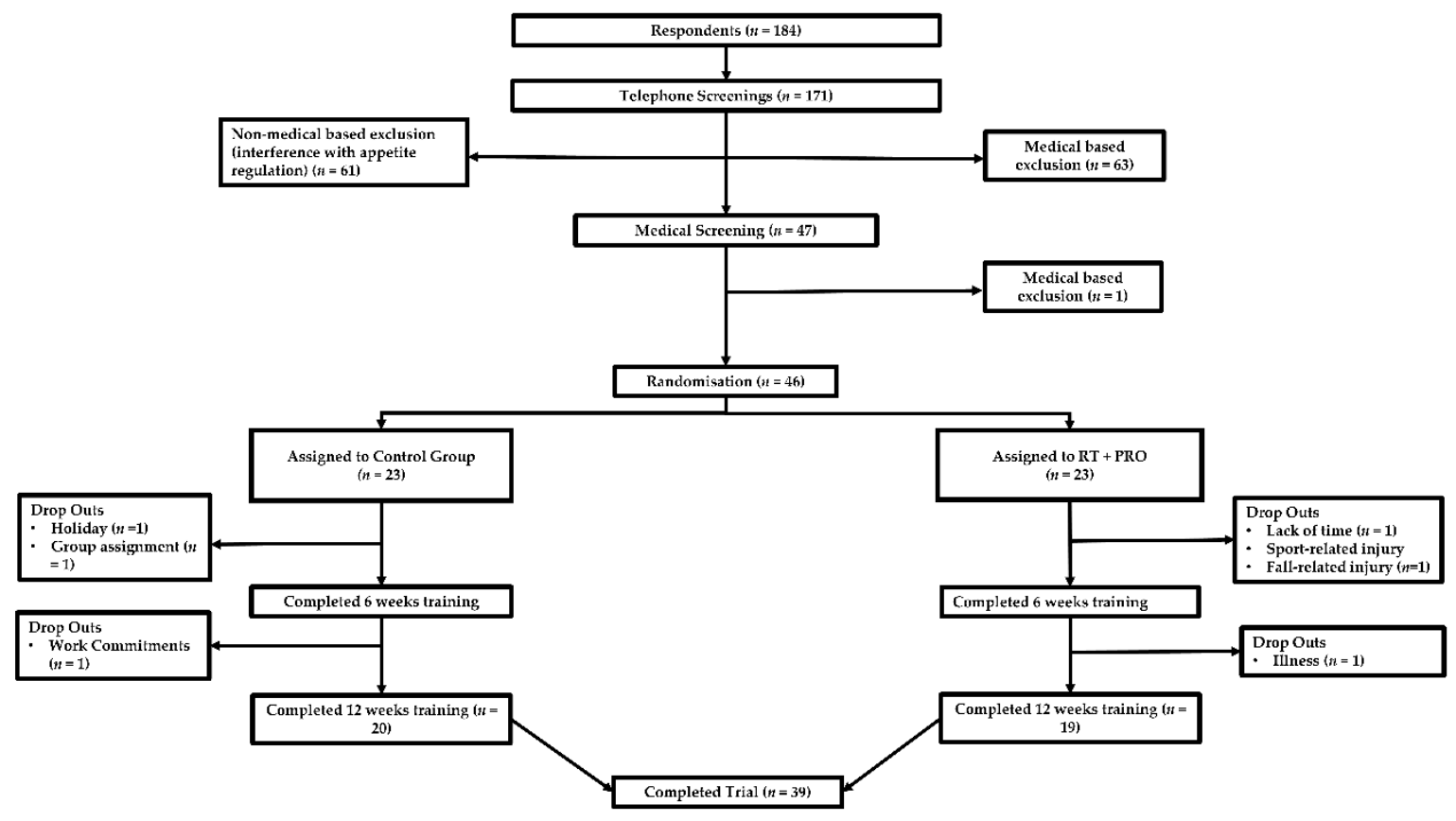

Figure 1. Participant flow from initial respondents to study completion. * Drop-outs related to training and/or testing. Injury and illness were not as a result of the intervention.

Table 1. Participant Characteristics (Mean \pm SD).

\begin{tabular}{ccc}
\hline & RT + PRO $(\boldsymbol{n = 1 9 )}$ & CON $(\boldsymbol{n}=\mathbf{2 0})$ \\
\hline Age (years) & $67 \pm 4$ & $65 \pm 4$ \\
Height $(\mathrm{m})$ & $1.67 \pm 5.3$ & $1.68 \pm 8.4$ \\
Body mass $(\mathrm{kg})$ & $72.4 \pm 9.6$ & $73.8 \pm 16.5$ \\
BMI $\left(\mathrm{kg} \cdot \mathrm{m}^{-2}\right)$ & $25.7 \pm 3.6$ & $26.2 \pm 6.1$ \\
\hline
\end{tabular}

Abbreviations: SD: Standard Deviation, RT + PRO: Resistance training and protein group, CON; control group, BMI: Body Mass Index.

The study obtained approval from the Leeds Beckett University Research Ethics Committee and was conducted in accordance with the Declaration of Helsinki (Application reference: 58906).

\subsection{Experimental Design}

A 15-week randomised control trial was conducted with the inclusion of two experimental groups (Figure 2). Two weeks of pre-testing (baseline) were conducted prior to the 12-week intervention which involved random allocation to either a control group (CON) or resistance training and protein supplementation group $(\mathrm{RT}+\mathrm{PRO})$. The immediate week following the completion of the 12-week intervention involved the post-testing. Participants were required to attend a total of six laboratory visits. Participants recorded their food intake for the $24 \mathrm{~h}$ prior to the first experimental trial; the quantity and timing of this intake were then replicated before each subsequent trial. Participants in both groups arrived at the laboratory after an overnight fast of $\geq 10 \mathrm{~h}$ and were required to avoid alcohol, caffeine and strenuous exercise in the $24 \mathrm{~h}$ preceding the trial. Two hours before the laboratory testing participants were required to consume $300 \mathrm{~mL}$ of water to ensure euhydration. Additional visits to the University gym were required for the participants who were assigned to the RT + PRO. 


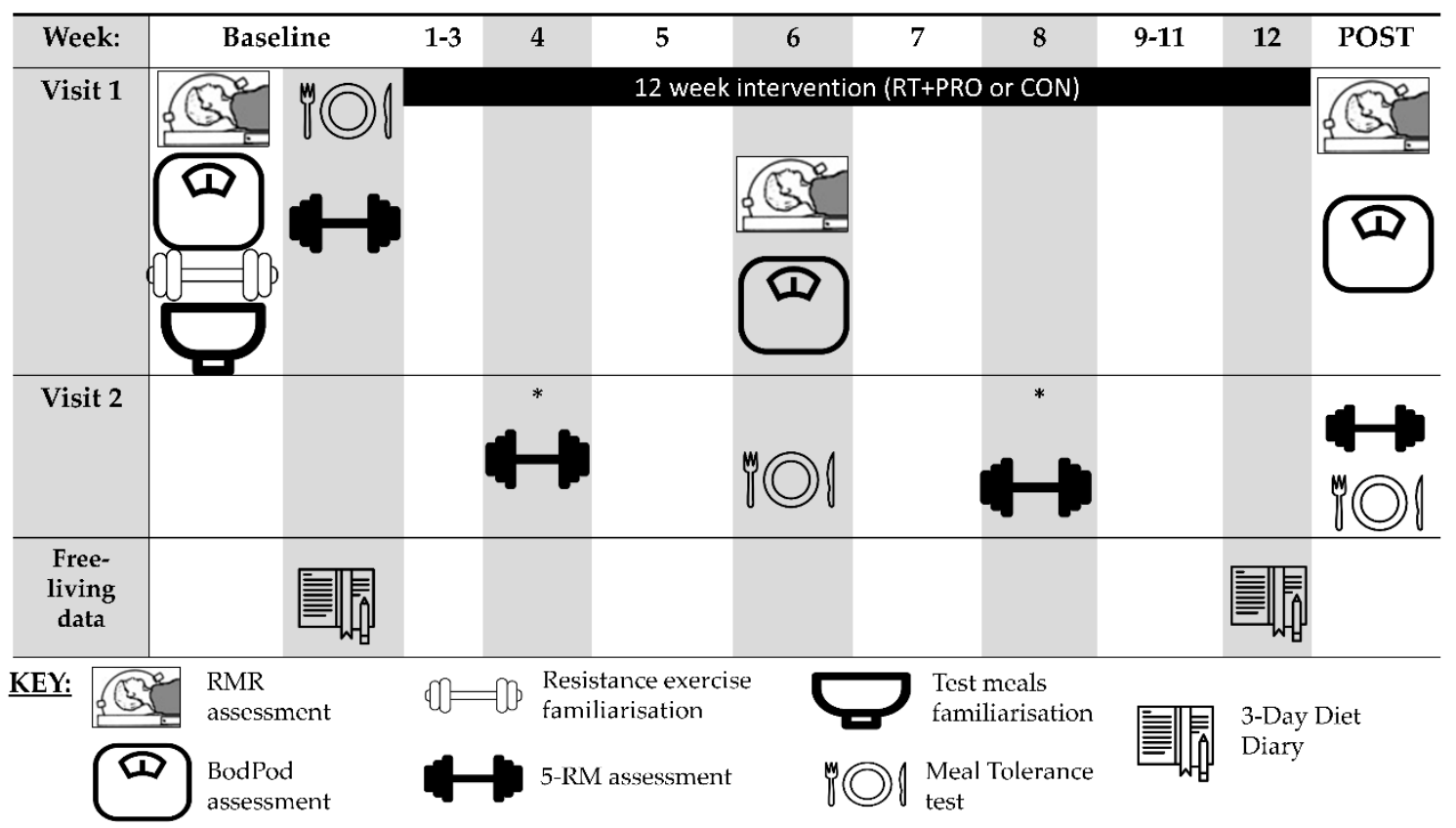

Figure 2. Schematic of the full randomised control trial including intervention and testing days. Participants were assigned to either the RT + PRO or CON during weeks 1-12. * indicates measures taken in RT + PRO only to adjust for training load.

\subsection{Pre-Testing (Baseline)}

On the first week of baseline testing, anthropometric variables were recorded. Due to the difficulty in the measurement of basal metabolic rate in a laboratory setting, resting metabolic rate was assessed instead. Previous research has shown that resting metabolic rate is typically $3 \%$ higher than basal metabolic rate [30,31]. Body composition assessment was subsequently conducted. Following this, all participants were familiarised to the standardised test meals and resistance exercise machines included in the randomised control trial. Participants were given verbal and written instructions on how to complete a three-day food diary for the assessment of daily EI. Participants were then provided with an example and a blank template document to complete the weighed food diary.

After the body composition measurement participants were matched for FFM scores and allocated into CON or RT + PRO. Block randomisation was used to assign equal sample numbers to each group of four participants (block). The block size was in fours which created a possible six sequences: these were $A A B B, A B A B, A B B A, B A A B, B A B A$, BBAA. This was repeated until the 46 participants were all assigned. This was done to ensure that baseline FFM would not be a confounding variable $[32,33]$. In the second visit of baseline testing, following the measurements of fasted subjective appetite and appetite hormone concentrations, a meal tolerance test (MTT) was conducted to assess postprandial appetite-related hormone concentrations, subjective appetite and ad libitum EI. Participants then completed a five-repetition maximum (5-RM) test to assess maximum strength. The $5 \mathrm{RM}$ scores were used to estimate the required workloads during the resistance exercise sessions for those assigned to RT + PRO. These initial preliminary visits were separated by $\geq 7$ days to prevent any influence of unaccustomed exercise on appetite and EI.

\subsection{Mid and Post-Testing (Week 6 and Week 12)}

All procedures conducted during pre-testing were repeated, in the same sequence, at week 6 and within 4 days of the final resistance training session (week 12), with the exception of the 5-RM and daily EI measures, which were repeated only at week 12 . Familiarisation sessions were not required at weeks 6 and 12. The procedures in week 12 were identical to week 6; however, a 5-RM was conducted following the MTT (see Figure 2). 
In all instances, resting metabolic rate was not conducted within the $48 \mathrm{~h}$ window following resistance exercise.

\subsection{Experimental Protocol}

Participants assigned to RT + PRO were required to visit Leeds Beckett University gym twice per week, with at least $48 \mathrm{~h}$ between training sessions, for a duration of 12 weeks. Participants were required to complete resistance training sessions twice weekly in accordance with the current ACSM guidelines [34]. The order in which the seven exercises were performed was seated row, leg press, chest press, leg extension, lat pull down, leg curl and shoulder press. For the first two weeks of the intervention, participants conducted 2 sets of 10-15 reps at $65-75 \%$ of the predicted 1-RM. Due to safety reasons 5-RM was to predict 1-RM [35]. This intensity was selected as research has shown intensities ranging from $65-75 \%$ result in enhancements in skeletal muscle mass in older adults [34]. From week three of the intervention, the number of sets performed for each exercise increased from two to three with a repetition range of 10-15. Two minutes' rest was provided between each set. For each of the aforementioned exercises, 5-RM strength was reassessed at week 4 and week 8 at the end of the four-week training cycle, and subsequently, the training load was adjusted accordingly. Each four-week training cycle started at $65 \%$ of the new predicted 1-RM and the training load was increased to promote progressive overload of skeletal muscle. All sessions were supervised by a qualified personal trainer.

Additionally, participants received two portions of whey protein (USN Blue Lab Whey) per day, which contained $15 \mathrm{~g}$ of protein each (30 g total, $169 \mathrm{kcal}$ per day). This portion was selected as previous research has shown two $15 \mathrm{~g}$ portions of protein was enough to stimulate a $1.3 \mathrm{~kg}$ increase in lean body mass in older adults alongside 12 weeks of resistance training [28]. Estimates of meal-level dietary protein intake find lower proteincontaining meals at breakfast and lunch which are suboptimal concerning stimulation of MPS, with only one higher protein-containing meal (normally dinner, 30-40 g protein) reaching a protein intake that is optimal for postprandial MPS [36,37]. Therefore, participants consumed $15 \mathrm{~g}$ of protein with breakfast and lunch. Participants assigned to CON were instructed to continue their current lifestyle as usual with no changes to physical activity or protein/EI.

\subsection{Outcome Measures}

\subsubsection{Resting Metabolic Rate}

Resting metabolic rate was measured via indirect calorimetry using a ventilated hood connected to a canopy (Cortex, Canopy, Leipzig, Germany) connected to an online gas analysis system (Metalyser 3B, Leipzig, Germany). Twenty-four hours before visiting the laboratory participants were told to avoid exercise. On the morning of experimental trials, participants used motorised transport where possible. Participants also used the lift and avoided the stairs to the laboratory to minimise exertion. Prior to use, the Metalyser was calibrated using reference gases, daily barometric pressure, and a $3 \mathrm{~L}$ volume syringe. Calibration gas of a known oxygen $(15 \%)$ and carbon dioxide $(5 \%)$ content was used, with calibration accepted as a deviation of $< \pm 0.1 \%$. Testing was conducted in accordance with guidelines established by Compher and colleagues [38]. Before the assessment of resting metabolic rate, participants were rested for $10 \mathrm{~min}$ in a dim lit room. After the rest period, the ventilated hood, which was connected to the Metalyser, was placed over the head of the participant, with the surrounding 'skirt' secured in place. During the measurement period, air flowed continuously into the hood, over the participant's head, whilst expired air was extracted at the same rate into the Metalyser. Participants remained quiet and still, but awake, in the supine position through the entire resting metabolic rate procedure. The room was maintained in low light, and noise was kept at a minimum $[39,40]$. The average room temperature across trials was $23.3 \pm 1.6{ }^{\circ} \mathrm{C}$. The expired fraction of oxygen and carbon dioxide were determined, and oxygen consumption $\left(\mathrm{VO}_{2}\right)$ and carbon dioxide production $\left(\mathrm{VO}_{2}\right)$ were calculated. During all tests expired air measurements were made 
continuously for $20 \mathrm{~min}$ and an average of the final $15 \mathrm{~min}$ of data was used for the calculation of non-protein respiratory exchange ratio (RER). The ratio of the volume of carbon dioxide produced to the volume of oxygen consumed was used to compute the RER, $\mathrm{VO}_{2}$ and $\mathrm{VCO}_{2}$ for each minute. The deviation around the mean was allowed to be no more than $10 \%$ for $\mathrm{VO}_{2}$ and $\mathrm{VCO}_{2}$ alongside an RER $<0.7$ or $>1$ to be confirmed as steady-state [38]. Daily resting metabolic rate was calculated from oxygen consumption and carbon dioxide production by the Weir formula [41].

\subsubsection{Body Composition \\ Air Displacement Plethysmography (BOD POD)}

Body composition was assessed by air displacement plethysmography, using the BOD POD (BOD POD ${ }^{\circledR}$, Life Measurement Instruments, Concord, CA, USA). After voiding participants were asked to change into tight-fitting swimwear which was the same during each visit. All jewellery was removed and participants were provided with a tightly fitted cap to eliminate the presence of trapped isothermal air [42]. A two-point calibration was performed as described previously by McCrory et al. [43]. Body volume was determined by the mean volume of air displaced when the participant was secured in the chamber. Thoracic gas volume $\left(\mathrm{V}_{\mathrm{TG}}\right)$ was predicted using the age-specific equation developed by Crapo et al. [44]; this was then used to adjust measured body volume estimated according to the methods described by the manufacturer [45]. The corrected body volume was used in combination with body mass to determine body density, from fat, lean weight and lung volume using the Siri Equation [46].

\subsubsection{Meal Tolerance Test}

Standardised Meals Familiarisation

Following body composition analysis, participants consumed the standardised breakfast meal provided at the onset of the meal tolerance test. Familiarisation was completed to confirm participants were happy to consume this meal during the experimental trials. Alongside the standardised breakfast meal familiarisation, participants were provided with $15 \mathrm{~g}$ of protein mixed with $400 \mathrm{~mL}$ of water to confirm they would be able to consume this amount and type of nutritional supplement if allocated to RT + PRO. Participants were also familiarised to the pasta meal to be provided at ad-libitum on completion of the meal tolerance test (see Figure 3).

\subsection{Breakfast Test Meal}

The standardised breakfast meal was calculated based on the total daily energy requirements of each participant. Daily energy requirement of the participants was calculated as resting metabolic rate multiplied by a physical activity level factor. A physical activity level factor of 1.40 was applied, representing the activity level of an individual who is predominantly chair bound during the experimental trial [47]. Twenty-two percent of total daily energy requirements were provided within this meal with a macronutrient distribution of $59 \% \mathrm{CHO}, 27 \%$ fat and $14 \%$ protein (mean $=447 \pm 88 \mathrm{kcal}$ ) to replicate reported EI and macronutrient distribution in older adults at breakfast meals [48]. The breakfast meal was jam on toast and consisted of white bread (Hovis, thick sliced), unsalted butter (Sainsbury's), strawberry jam (Sainsbury's) and semi-skimmed milk.

\subsection{Subjective Appetite Sensations}

Hunger, satiety, fullness and prospective food consumption were assessed by $100 \mathrm{~mm}$ visual analogue scales (VAS) [49]. The baseline measure was obtained immediately prior to the standardised breakfast meal $(t=0)$. After the completion of the standardised breakfast meal, participants completed another VAS, with subsequent measures obtained every half an hour for $180 \mathrm{~min}$ (see Figure 3). A composite subjective appetite score was calculated using the following formula: composite appetite score $=$ (hunger + prospective food consumption $+(100-$ fullness $)+(100-$ satisfaction $) / 4)$ [50]. This single composite score 
was used for ease of data analysis and presentation, as it has been shown that, with the original six question VAS technique [51], the scores for each question co-vary to a large extent [50]. A higher value is associated with a greater appetite sensation. All visual analogue scales were measured in duplicate by the same researcher to ensure accuracy.

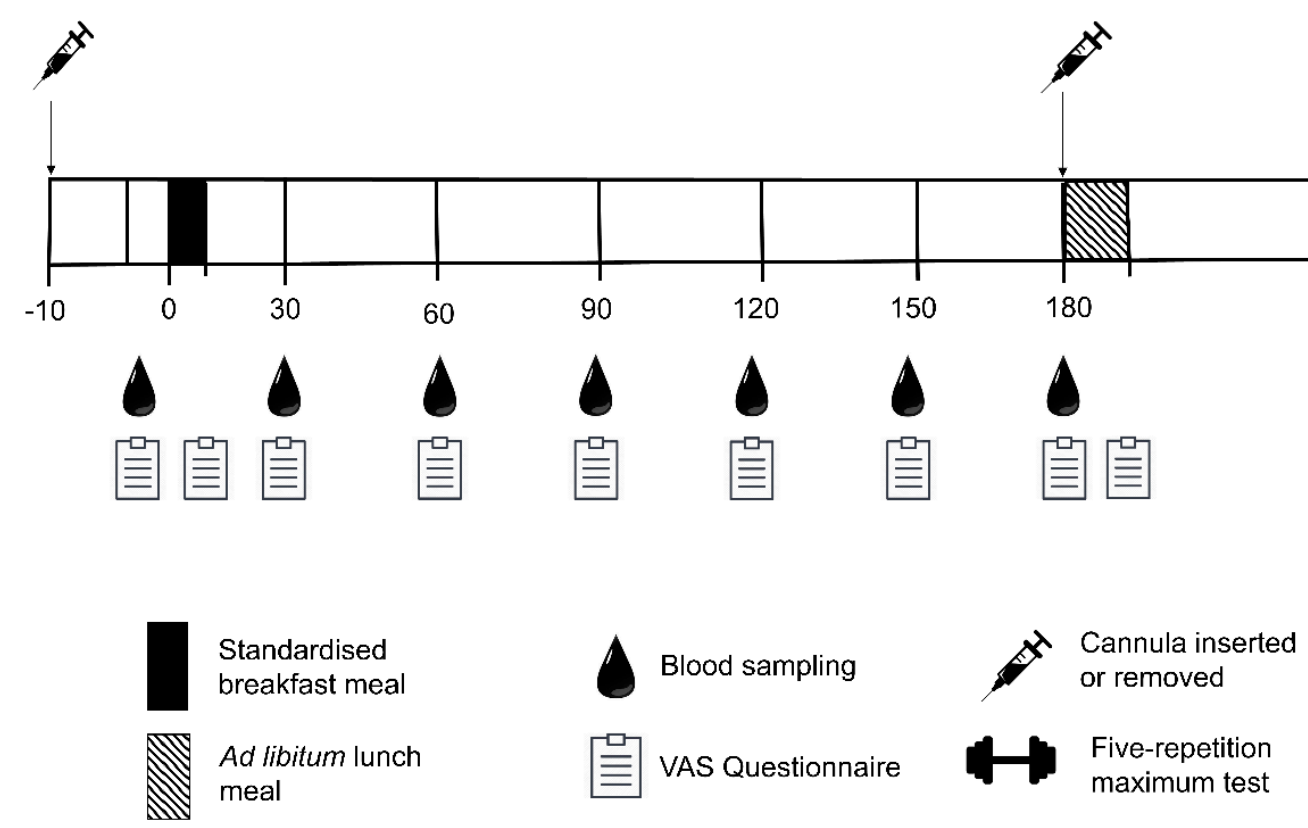

Figure 3. Schematic representation of meal tolerance test conducted at baseline, week 6 and 12. * Indicates procedures that were taken during baseline and Week 12 only. VAS; visual analogue scale.

\subsection{Blood Sampling}

A 22-gauge cannula was inserted into the antecubital vein on arrival to the laboratory. After the insertion of the cannula, the participant remained relaxed for $10 \mathrm{~min}$ before the fasting sample was taken. This procedure has been shown to stimulate the vagus nerve, which can affect appetite related-hormones leading to reduced appetite sensations [52]. Samples were obtained prior to the ingestion of the standardised breakfast meal (fasted) and then every $30 \mathrm{~min}$ following the initiation of the standardised breakfast meal for $180 \mathrm{~min}$. Cannulas were kept patent by flushing with $5 \mathrm{~mL}$ non-heparinised saline $(0.9 \%$ sodium chloride, Baxter Healthcare Ltd., Norfolk, UK) after each sample and at regular intervals between sampling.

To avoid dilution of blood samples with saline, the first $2 \mathrm{~mL}$ of each sample drawn was discarded. Blood samples were drawn in $10 \mathrm{~mL}$ volumes into pre-chilled tubes containing the anticoagulant $\mathrm{K}_{2}$ EDTA (Vacutainer, Becton Dickinson, NJ, USA). Tubes were inverted 15 times to ensure mixing with anticoagulant. To prevent any extraneous influences from postural changes, all blood samples were collected whilst the participant was seated [53].

Immediately after collection, samples were centrifuged (ALC, PK130R, Winchester, VA, USA) for $10 \mathrm{~min}$ at $1500 \times g$ and a temperature of $4{ }^{\circ} \mathrm{C}$. The supernatant of each sample was then removed, separated into $1 \mathrm{~mL}$ cryovials and initially stored at $-40{ }^{\circ} \mathrm{C}$. Samples were then transferred to $-80^{\circ} \mathrm{C}$ for later analysis.

\subsection{Assessment of Energy Intake}

\subsubsection{Ad Libitum Energy Intake}

After the completion of the MTT and cannula removal, EI was assessed using a standardised ad libitum pasta meal. The ad libitum meal was designed to closely align with the UK dietary guidelines [54] for macronutrient proportions (52\% carbohydrate, $34 \%$ fat 
and $14 \%$ protein). The pasta-based meal consisted of penne pasta (Sainsbury's), cheddar cheese (Sainsbury's), tomato sauce (Sainsbury's) and olive oil (Sainsbury's). Pasta was cooked for $15 \mathrm{~min}$ in unsalted water at $700 \mathrm{~W}$ before being mixed with the remaining ingredients and re-heated for $2 \mathrm{~min}$ at $700 \mathrm{~W}$. Participants consumed the lunch in isolation to avoid any social influence on food intake. No other visual or food cues were present. A bowl of the aforementioned meal was provided by an investigator and participants were instructed to eat until 'comfortably full', with no time limit set for eating. This bowl was replaced before the participant had emptied it to prevent the completion of a bowl signalling satiety, with minimal interaction and this process continued until the participant was comfortably full. Food intake was calculated as the weighted difference in food before and after eating [55]. Water was available at ad libitum during participants' first trial and standardized for each subsequent trial.

\subsubsection{Daily Energy Intake}

Daily EI was measured at baseline and at Week 12 using three-day weighed food diaries. Participants were provided with instructions on how to complete the diary which included the type, quantity, the preparation of cooking and timing of this intake. The three-day food diary involved the analysis of three consecutive days including at least one weekend day. Upon receiving a completed food diary from a participant, a member of the research team initially checked the clarity and detail of information provided. The participant was then asked to provide any additional clarity or detail required for dietary analysis. The food diary was analysed using online software analysis (Nutritics Ltd., Dublin, Ireland).

\subsection{Maximal Strength}

The multiple maximum strength test method has been demonstrated to be suitable for prescribing the intensity of strength training [56]. The reproducibility of 5-RM strength testing in older adults has been validated [57], and therefore the use of 5-RM testing was employed in this thesis. The order in which the resistance exercises were conducted matched the order during the resistance training intervention and familiarisation. The 5-RM protocol was adapted from Haff and Triplett [58]. The test was initiated with 10 repetitions. This was reduced with each set and a load of $5-10 \%$ was added. Once participants had reached 5 repetitions the load was continuously added at the end of each set. Based on the participants' RPE scores during the familiarisation trial, a starting weight which was estimated to score 5 on the RPE scale was determined by the researcher. Participants were allocated at least four minutes' rest period before the next attempt to allow sufficient recovery [59]. A 5-RM attempt was confirmed when participants provided an RPE of 10 referring to "very, very heavy- maximum exertion". If the participant could not complete five repetitions with good technique, then the previous weight was used for the 5-RM score.

One-repetition maximum value for the resistance exercise was then predicted using the formula by Mayhew and Ball [35]:

$$
1-R M=\frac{W}{\left(52.2+41.9 e^{-0.55 \cdot R)} / 100\right.}
$$

This formula was chosen since it was evidenced to have high relative accuracy and low absolute error providing a safe range 1-RM value for older adults starting a resistance training programme [60].

\subsection{Analysis of Blood Samples}

The enzyme-linked immunosorbent assay (ELISA) technique was used to determine leptin and insulin concentrations (ELISA kit, Millipore, MA, USA). To eliminate interassay variation, all samples from each participant were analysed on the same plate when using the plate reader. The sensitivity of these ELISA kits were $0.2 \mathrm{ng} / \mathrm{mL}$ and $1 \mu \mathrm{U} / \mathrm{mL}$ respectively and the within batch coefficients of variation were; leptin $4.1 \%$ and insulin $4.9 \%$. 


\subsection{Statistical Analysis}

With expected adherence rates of $69 \%$, a sample of 46 participants (23 per arm) allowed for the completion of a minimum of 30 participants $(n=15$ per arm). The study finished with 39 participants $(\mathrm{CON}=20$ and $\mathrm{RT}+\mathrm{PRO}=19)$ All descriptive data were analysed using SPSS for Windows version 26.0 software (SPSS, Chicago, IL, USA). Baseline differences between groups were assessed using Welch's t-test for all outcome measures. To compare differences between the experimental group (RT + PRO) and control $(\mathrm{CON})$, a linear mixed-effects model analysis was used [61]. Group (CON or RT + PRO), trial (baseline, week 6 and week 12) and time (0 to $120 \mathrm{~min}$ ) were used as repeated categorical variable for measures that were repeated within a trial (VAS and blood analytes) [62-64].

Post-hoc analysis was completed on significant fixed effects using the Bonferroni adjustment and supplemented with Cohen's $d$ effect sizes interpreted as $\leq 0.2$ trivial, $>0.2$ small, $>0.6$ moderate, $>1.2$ large, $>2$ very large and $>4$ extremely large [65]. Descriptive data analysis, individual change scores and $95 \%$ confidence intervals were calculated for baseline and week 12 . Appetite values were compared with the minimal clinically important difference [49]. All blood parameters were compared for fasting concentrations and postprandial area-under-the-curve (AUC). AUC was calculated using the trapezoidal method.

Following the results from the linear mixed models, analyses were undertaken to examine the extent to which the effects of group on changes from baseline to Week 12 in EI were accounted for by changes from baseline to Week 12 in FFM, FM, RMR, and postprandial AUC subjective appetite. Ad libitum EI was used as the dependent variable due to the known limitations in underreporting using free-living measures such as food diaries [66]. To assist in identifying variables that may account for the effects of group effects on changes in ad libitum EI, we applied a procedure equivalent to the four assumptions of mediation analysis explained previously by $[65,66]$. Using ANOVA and ANCOVA produces identical results to regression analyses and are conceptually equivalent to regression [67]. First, the independent variable (i.e., group) should affect the dependent variable. Second, the independent variable should affect the mediating variable(s). Therefore, MANOVAs with follow-up ANOVAs were conducted to initially determine group differences for changes in EI (dependent variable) as well as FFM, FM, RMR, and postprandial AUC subjective appetite. The last two criteria are that the mediating variable(s) should affect the dependent variable when adjusting (or controlling) for the independent variable, and the effect of the independent variable on the dependent variable should be reduced in the presence of the mediating variable(s). To address the final two criteria ANCOVAs were conducted. Specifically, we examined the change in the main effect of the independent variable (group) on the dependent variable (change in ad libitum EI) after adjusting for differences in the covariates (i.e., changes in FFM, FM, RMR, and AUC postprandial subjective appetite). The magnitude of change in effect (calculated as $\eta^{2}$ ) associated with the group factor when a variable is added as a covariate reflects the extent to which this variable (covariate) accounts for group differences in EI [68]. Therefore, we used the above assumptions of mediation to help provide a conservative approach in determining which variables would be worth including as covariates in these analyses, and thereby consider as having a noteworthy contribution in accounting for the effects of the intervention on changes in ad libitum EI. Based on evidence that males and females exhibit similar appetite, EI, and gut hormone responses to exercise- and diet-induced energy deficits [64], data from both sexes were combined for analysis.

Based on evidence that males and females exhibit similar appetite, EI, and gut hormone responses to exercise- and diet-induced energy deficits [69], data from both sexes were combined for analysis.

\section{Results}

After initial contact from 184 respondents, further explanation of the experimental trials and screening took place. Participants were excluded for either non-medical based reasons, which included: a history of or current smoker, actively attempting/attempted 
to lose weight within the last 6 months, could not commit to the full 15-week trial, or taken part in resistance exercise within the last 6 months. Participants were excluded on a medical basis if they were taking medication or had any conditions known to affect appetite regulation. The first 46 participants, who were eligible to participate and verbally agreed to take part in the study, were selected for participation in the 15-week study. Thirty-nine participants completed the full 15 weeks and all experimental trials (see Figure 1).

\subsection{Compliance}

Participants, who completed the intervention exercised at least $92 \%$ (22 out of 24) of the expected sessions (average $94 \pm 4 \%$ ). Participants also consumed at least 93\% (157 out of 168) protein portions (average $96 \pm 2 \%$ ). Reasons for missed trials included holidays (maximum missed sessions $=2$ ). Protein was missed due to forgetting to take provided portions.

\subsection{Baseline Paramenters}

The only between group difference that was identified at baseline was fasted insulin concentrations. Fasted insulin was significantly lower in RT + PRO compared to CON at baseline (see Table 2). There were also no differences in maximal strength between groups across all exercises $(\geq 0.186)$.

Table 2. Baseline characteristics of the resistance training and protein supplementation (RT $+\mathrm{PRO})$ and control (CON).

\begin{tabular}{cccc}
\hline & RT + PRO & CON & $p$-Value \\
\hline Fat-free mass $(\mathrm{kg})$ & $50.5 \pm 2.2$ & $49.2 \pm 2.8$ & 0.773 \\
Body Weight $(\mathrm{kg})$ & $72.4 \pm 9.3$ & $73.8 \pm 16.1$ & 0.905 \\
Fat mass $(\mathrm{kg})$ & $24.7 \pm 9.1$ & $21.9 \pm 5.3$ & 0.336 \\
Resting metabolic rate $(\mathrm{kcal} / \mathrm{day})$ & $1543 \pm 67$ & $1395 \pm 65$ & 0.297 \\
Ad libitum energy intake $(\mathrm{kcal})$ & $448 \pm 42$ & $417 \pm 41$ & 0.543 \\
Daily energy intake $(\mathrm{kcal} / \mathrm{day})$ & $1987 \pm 122$ & $2234 \pm 128$ & 0.211 \\
Fasted subjective appetite $(\mathrm{mm})$ & $67 \pm 16$ & $66 \pm 15$ & 0.620 \\
Subjective appetite AUC $\left(\mathrm{mm} \cdot \mathrm{min}^{-1}\right)$ & $44 \pm 15$ & $39 \pm 14$ & 0.205 \\
Fasted leptin $(\mathrm{pg} \cdot \mathrm{mL})$ & $20.2 \pm 22.4$ & $25.4 \pm 30.2$ & 0.549 \\
Leptin AUC $\left(\mathrm{pg} \cdot \mathrm{mL} \cdot \mathrm{min}^{-1}\right)$ & $16.8 \pm 17.7$ & $21.4 \pm 27.9$ & 0.551 \\
Fasted insulin $\left(\mu \mathrm{IU} \cdot \mathrm{mL}^{-1}\right)$ & $43.0 \pm 11.6$ & $50.6 \pm 17.2$ & $0.039 *$ \\
Insulin AUC $\left(\mu \mathrm{IU} \cdot \mathrm{mL} \cdot \mathrm{min}^{-1}\right)$ & $13.2 \pm 5.2$ & $19.4 \pm 45.0$ & 0.117
\end{tabular}

Values are mean (SE), $n=20(\mathrm{CON})$ and $n=19(\mathrm{RT}+\mathrm{PRO})$. An asterisk $\left(^{*}\right)$ indicates significant differences between groups.

\subsubsection{Fat-Free Mass (FFM)}

A significant group ${ }^{*}$ trial interaction $(p=0.002)$ and trial effect was observed for FFM $(p=0.004)$. However, there were no group effects $(p=0.582)$ Fat-free mass significantly increased in RT + PRO from baseline to Week $12(+1.2 \mathrm{~kg} ; p=0.046 ; d=0.13 ; 95 \% \mathrm{CI}=-1.899$ to -0.592$)$, and from Week 6 to Week $12(+0.7 \mathrm{~kg} ; p<0.001 ; d=0.07 ; 95 \% \mathrm{CI}=-1.317$ to $-0.592)$. There was no change in FFM from baseline to Week 6 in RT + PRO ( $p=0.097)$. There were no changes in FFM in CON from baseline to week $6(p=1.000)$ or week 12 $(p=0.284)$.

\subsubsection{Fat Mass (FM)}

There was no significant effect for group $(p=0.202)$, trial $(p=0.226)$ and no significant group ${ }^{*}$ trial interaction effect $(p=0.168$, see Figure 4$)$ for fat mass. 


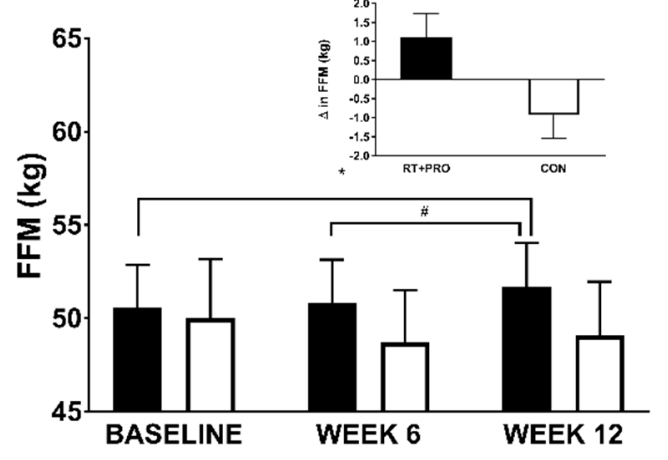

(a)

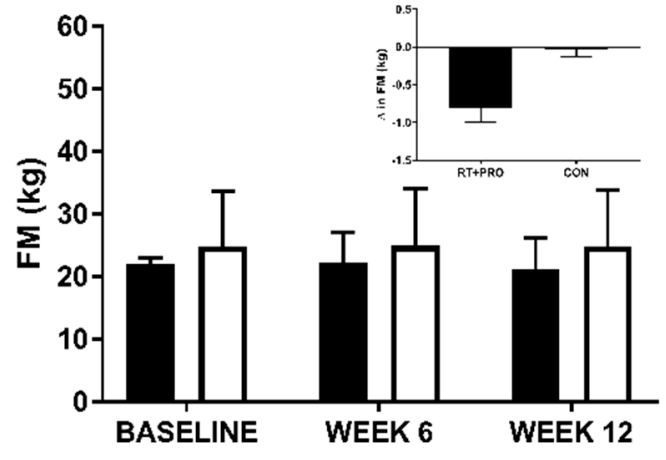

(b)

Figure 4. FFM (a) and FM (b) in CON (white bars; $n=20$ ) and RT + PRO (black bars; $n=19$ ) at baseline week, 6 and 12. An Asterisk $\left(^{*}\right)$ represents a significant difference from baseline to Week 12 , a hashtag (\#) represents differences from Week 6 to Week 12. The insert graph shows the change from baseline to Week 12. Values are presented as mean \pm SE. $\mathrm{FFM}=$ Fat-free mass.

\subsubsection{Body Weight}

There was a significant group ${ }^{*}$ trial interaction effect $(p=0.021)$ and trend for trial main effect $(p=0.060)$. There was no group effect $(p=0.936)$. An increase from baseline to Week 12 was observed in RT $+\mathrm{PRO}(+0.5 \mathrm{~kg}, p=0.092 ; d=-0.04 ; 95 \% \mathrm{CI}=-1.108$ to 0.059$)$. Weight significantly increased in RT + PRO from baseline to week $6(+0.8 \mathrm{~kg}$; $p=0.002 ; d=-0.30 ; 95 \% \mathrm{CI}=0.262$ to 1.429 ). However, there was no difference in weight from week 6 to week 12 of the intervention in RT + PRO $(-0.3 \mathrm{~kg}, p=0.545 ; d=0.00 ; 95 \%$ $\mathrm{CI}=-0.262$ to 0.904$)$. There were no differences in CON from baseline to Week $6(p=1.000)$ and baseline to Week 12 ( $p=1.000$; Figure 5).

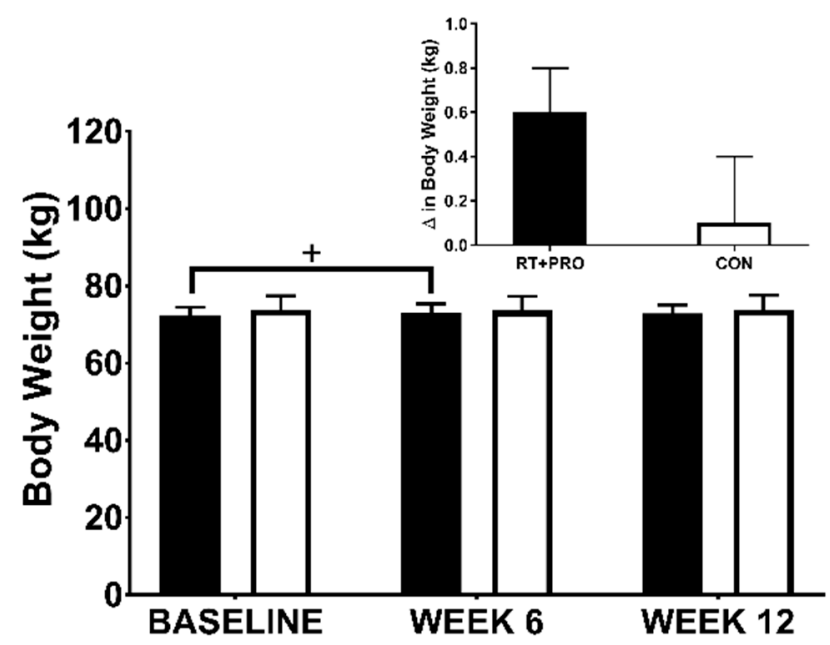

Figure 5. Body weight in CON (white bars; $n=20$ ) and RT + PRO (black bars; $n=19$ ) groups during baseline week 6 and 12. A addition symbol (+) represents differences from baseline to Week 6 . The insert graph shows the change from baseline to Week 12 . Values are presented as mean $\pm \mathrm{SE}$.

\subsubsection{Resting Metabolic Rate}

There was no significant main effect for group $(p=0.143)$, trial $(p=0.668)$ and no significant group*trial interaction effect $(p=0.283$; Figure 6$)$ for daily resting metabolic rate. 


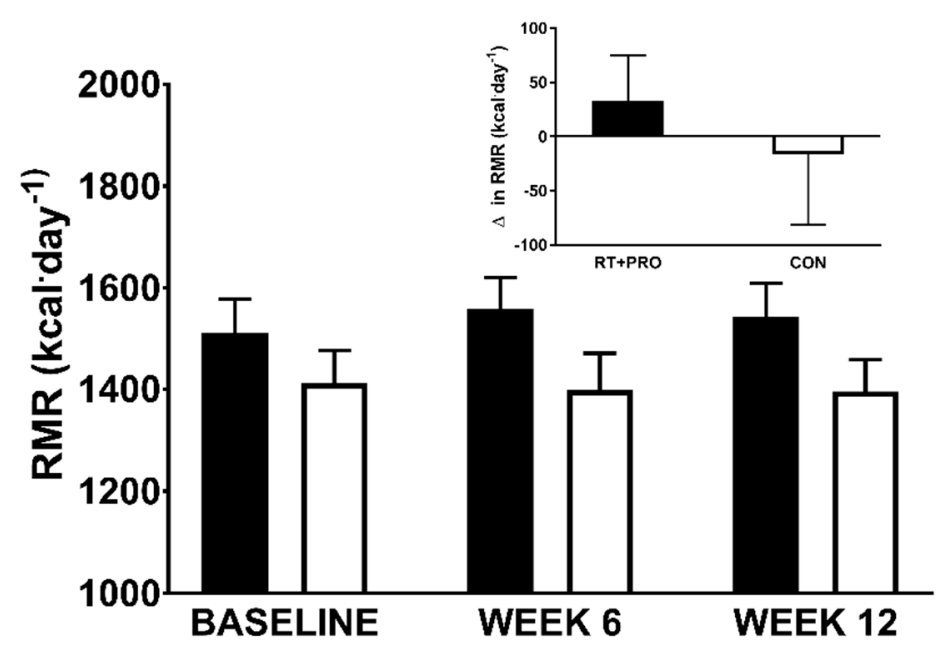

Figure 6. RMR in CON (white bars; $n=20$ ) and RT + PRO (black bars; $n=19$ ) groups during baseline week 6 and 12. + represents differences from baseline to Week 6 . The insert graph shows the change from baseline to Week 12 . Values are presented as mean \pm SE. RMR $=$ resting metabolic rate.

\subsection{Subjective Appetite}

Fasted subjective appetite did not reveal main effects for group $(p=0.768)$, or a group $*$ trial interaction effect $(p=0.629)$. However, there was a significant effect across trial $(p=0.002)$. Subjective appetite sensations decreased from baseline to Week 12 $\left(-6 \mathrm{~mm} \cdot \mathrm{min}^{-1} ; p=0.007 ; d=-0.50 ; 95 \% \mathrm{CI}=-13\right.$ to $\left.-2 \mathrm{~mm} \cdot \mathrm{min}^{-1}\right)$ and Week 6 to Week $12(-5 \mathrm{~mm} ; p=0.008 ; d=0.43 ; 95 \% \mathrm{CI}=-13$ to $-2 \mathrm{~mm})$ irrespective of group (See Table 3). However, no changes occurred from baseline to week $6(p=1.000)$. Postprandial appetite perceptions for AUC revealed a significant group $*$ trial interaction $(p=0.047)$ and significant group effect $(p=0.027)$. Postprandial subjective appetite was significantly higher in RT + PRO compared with the CON at Week $12\left(+8 \mathrm{~mm} \cdot \mathrm{min}^{-1} ; p=0.004 ; d=0.40 ; 95 \%\right.$ $\mathrm{CI}=5$ to $\left.23 \mathrm{~mm} \cdot \mathrm{min}^{-1}\right)$. In the RT $+\mathrm{PRO}$ postprandial subjective appetite increased significantly from baseline to Week $12\left(+8 \mathrm{~mm} ; p=0.012 ; d=0.24 ; 95 \% \mathrm{CI}=-13\right.$ to $\left.-1 \mathrm{~mm} \cdot \mathrm{min}^{-1}\right)$ and Week 6 to Week $12\left(+5 \mathrm{~mm} \cdot \mathrm{min}^{-1} ; p=0.042 ; d=0.19 ; 95 \% \mathrm{CI}=-9\right.$ to $\left.-2 \mathrm{~mm} \cdot \mathrm{min}^{-1}\right)$. No differences were observed from baseline to week $6(p=0.350)$. Postprandial subjective appetite did not differ across baseline, week 6 and week 12 in CON ( $p=1.00$ for all; see Table 4).

Table 3. Fasted subjective appetite sensations and circulating hormones concentrations at baseline, week 6 and Week 12 during the meal tolerance test in RT $+\mathrm{PRO}$ and $\mathrm{CON}$.

\begin{tabular}{|c|c|c|c|c|}
\hline & Baseline & Week 6 & Week 12 & $\Delta$ from Baseline to Week 12 \\
\hline \multicolumn{5}{|c|}{ Subjective appetite (mm) } \\
\hline $\mathrm{RT}+\mathrm{PRO}$ & $71 \pm 16$ & $65 \pm 17$ & $66 \pm 15$ & 5 \\
\hline $\mathrm{CON}$ & $75 \pm 15$ & $67 \pm 18$ & $65 \pm 14$ & 10 \\
\hline \multicolumn{5}{|c|}{ Leptin $\left(\mathrm{pg} \cdot \mathrm{mL}^{-1}\right)$} \\
\hline $\mathrm{RT}+\mathrm{PRO}$ & $20.2 \pm 22.4$ & $17.5 \pm 17.8$ & $27.6 \pm 44.6$ & 7.4 \\
\hline $\mathrm{CON}$ & $25.4 \pm 30.2$ & $27.3 \pm 33.9$ & $22.6 \pm 27.4$ & -2.8 \\
\hline \multicolumn{5}{|c|}{ Insulin $\left(\mu \mathrm{IU} \cdot \mathrm{mL}^{-1}\right)$} \\
\hline $\mathrm{RT}+\mathrm{PRO}$ & $13.2 \pm 5.2$ & $14.7 \pm 6.6$ & $16.4 \pm 12.4$ & 3.2 \\
\hline $\mathrm{CON}$ & $19.4 \pm 16.6$ & $22.9 \pm 22.0$ & $18.2 \pm 15.4$ & -1.2 \\
\hline
\end{tabular}

Values are mean $\pm \mathrm{SD}, \mathrm{CON} ; n=20$ and RT $+\mathrm{PRO} ; n=19$.

\subsection{Appetite-Relate Hormone Concentrations}

There were no main effects revealed for group ( $p \geq 0.198)$, trial $(p \geq 0.244)$, or group*trial interaction $(p \geq 0.100)$ for fasted (Table 3 ) or postprandial (Table 4) leptin and insulin circulating concentrations. 
Table 4. AUC (150 min) for subjective appetite sensations and circulating hormones concentrations at baseline, Week 6 and Week 12 during the meal tolerance test in RT + PRO and CON.

\begin{tabular}{ccccc}
\hline & Baseline & Week 6 & Week 12 & $\Delta$ from Baseline to Week 12 \\
\hline $\begin{array}{c}\text { Subjective appetite } \\
\left(\mathrm{mm} \cdot \mathrm{min}^{-1}\right)\end{array}$ & & & & $8^{*}$ \\
$\mathrm{RT}+\mathrm{PRO}$ & & & $52 \pm 14$ & 5 \\
$\mathrm{CON}$ & $44 \pm 15$ & $39 \pm 17$ & $44 \pm 17$ & -2.0 \\
Leptin $\left(\mathrm{pg} \cdot \mathrm{mL} \cdot \mathrm{min}^{-1}\right)$ & $39 \pm 14$ & & & -1.5 \\
$\mathrm{RT}+\mathrm{PRO}$ & $21.4 \pm 27.9$ & $15.6 \pm 15.3$ & $19.4 \pm 20.4$ & -0.1 \\
$\mathrm{CON}$ & $16.8 \pm 17.7$ & $14.8 \pm 12.3$ & $15.3 \pm 15.7$ & -4.4 \\
Insulin $\left(\mu \mathrm{IU} \cdot \mathrm{mL} \cdot \mathrm{min}^{-1}\right)$ & & & \\
RT $+\mathrm{PRO}$ & $43.0 \pm 11.6$ & $48.6 \pm 17.2$ & $42.9 \pm 14.3$ & \\
$\mathrm{CON}$ & $50.6 \pm 17.2$ & $47.6 \pm 15.2$ & $45.0 \pm 20.6$ & \\
\hline
\end{tabular}

Values are mean $\pm \mathrm{SD}, \mathrm{CON} ; n=20$ and $\mathrm{RT}+\mathrm{PRO} ; n=19$. An Asterisk $\left(^{*}\right)$ represents a significant difference from baseline to Week 12.

\subsection{Energy Intake (EI) \\ 3.5.1. Ad Libitum EI}

A group*trial interaction $(p=0.040)$ and trial effect were observed for ad libitum EI $(p=0.012)$. There was no main effect for group $(p=0.218)$. The RT + PRO showed a significant increase in ad libitum EI from baseline to week $12(+119 \mathrm{kcal} ; p=0.001, d=0.60$; $95 \% \mathrm{CI}=-41$ to $197 \mathrm{kcal})$ and week 6 to week $12(+80 \mathrm{kcal} ; p=0.042 ; d=0.36 ; 95 \% \mathrm{CI}=2$ to $158 \mathrm{kcal})$. There was no change in ad libitum EI from baseline to week $6(p=0.673)$. There was no difference in ad libitum EI across trials in CON from baseline to Week $12(p=0.803)$ or Week 6 to Week 12 ( $p=1.000$; see Figure 7).

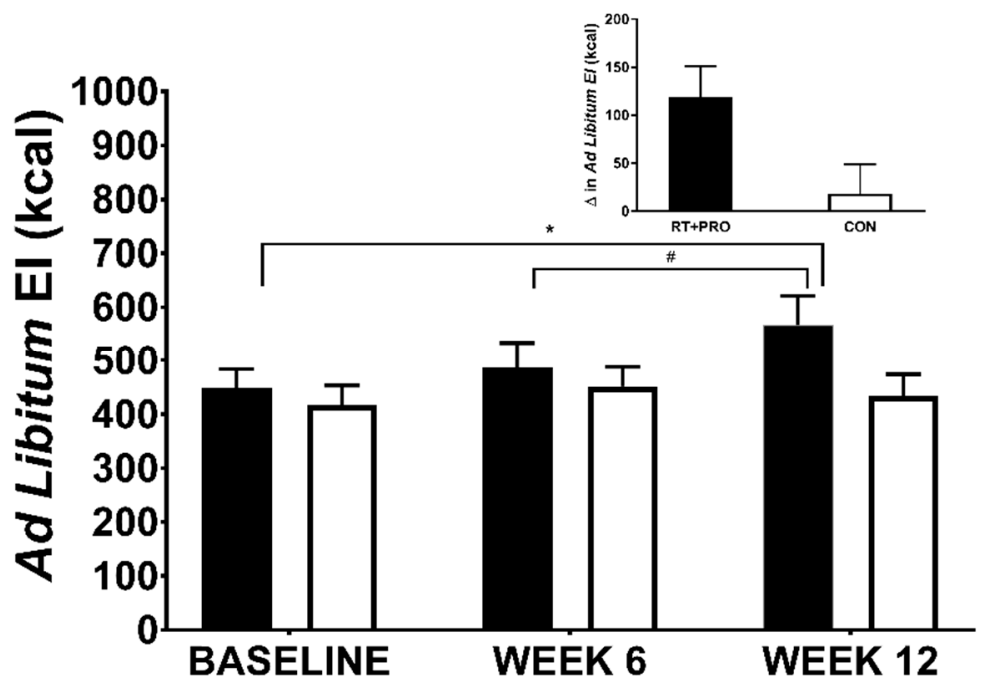

Figure 7. Ad libitum EI in CON (white bars; $n=20$ ) and RT + PRO (black bars; $n=19$ ) groups during baseline, week 6 and 12. An Asterisk $\left(^{*}\right)$ represents a significant difference from baseline to Week 12, a hashtag (\#) represents differences from Week 6 to Week 12. The insert graph shows the change in ad libitum EI from baseline to Week 12. Values are presented as mean $\pm \mathrm{SE}$. EI = Energy Intake, $\mathrm{RT}+\mathrm{PRO}=$ resistance training and protein group, $\mathrm{CON}=$ control group.

\subsubsection{Daily EI}

There was a significant group*trial interaction for daily EI $(p=0.010)$. However, there was no group $(p=0.689)$ or trial $(p=0.505)$ effects. Daily EI increased from baseline to Week 12 in RT + PRO (mean difference $=+133 \mathrm{kcal} ; d=0.29 ; 95 \% \mathrm{CI}=1729$ to $2245 \mathrm{kcal}$; Figure 8; Table 5). The CON decreased from baseline to Week 12 (mean difference $=-223 \mathrm{kcal}$; $d=0.41 ; 95 \% \mathrm{CI}=1753$ to $2269 \mathrm{kcal})$. 


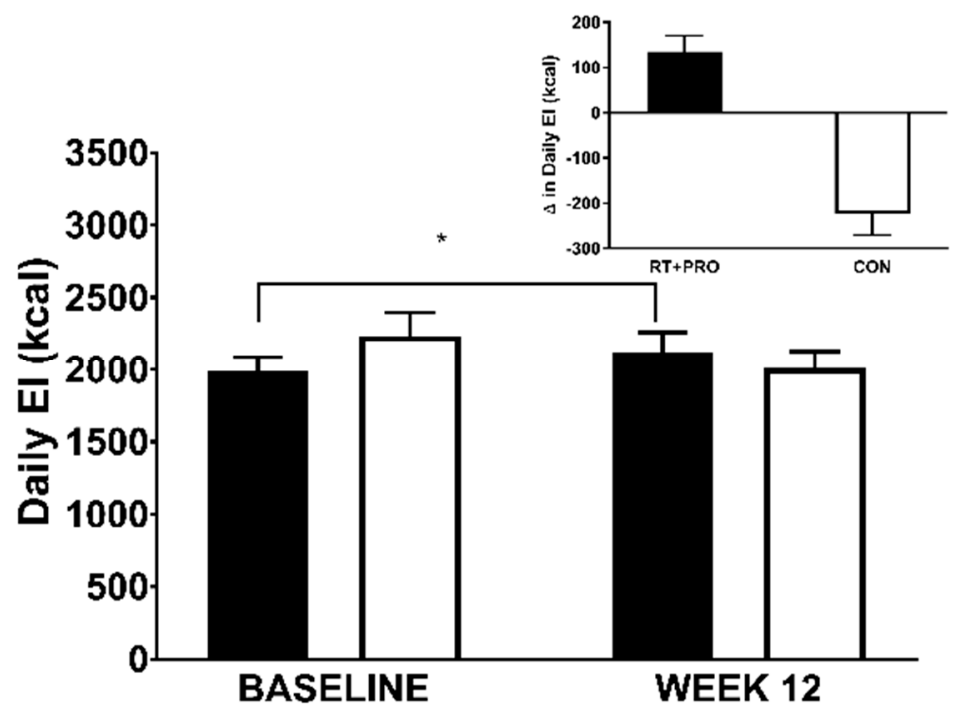

Figure 8. Daily EI in CON (white bars; $n=15$ ) and RT + PRO (black bars; $n=15$ ) groups for baseline and week 12. An Asterisk (*) represents a significant difference from baseline to Week 12. Values are presented as mean $\pm \mathrm{SE}$. EI = Energy Intake, $\mathrm{RT}+\mathrm{PRO}=$ resistance training and protein group, $\mathrm{CON}$ $=$ control group .

Table 5. Daily energy intake and macronutrient intake across groups with and with the protein supplementation for RT + PRO.

\begin{tabular}{|c|c|c|c|}
\hline & Baseline & Week 12 & $\Delta$ from Baseline to Week 12 \\
\hline \multicolumn{4}{|l|}{ Energy Intake (kcal) } \\
\hline RT + PRO (total) & $1987 \pm 396$ & $2120 \pm 533$ & +133 \\
\hline RT + PRO (-protein supplement) & $1987 \pm 396$ & $1953 \pm 507$ & +34 \\
\hline $\mathrm{CON}$ & $2234 \pm 634$ & $2010 \pm 448$ & -224 \\
\hline \multicolumn{4}{|l|}{ Protein Intake (g) } \\
\hline RT + PRO (total) & $85 \pm 21$ & $103 \pm 26$ & +18 \\
\hline RT + PRO (-protein supplement) & $85 \pm 21$ & $73 \pm 20$ & -12 \\
\hline CON & $85 \pm 18$ & $77 \pm 19$ & -8 \\
\hline \multicolumn{4}{|l|}{ Carbohydrate Intake (g) } \\
\hline $\mathrm{RT}+\mathrm{PRO}$ (total) & $228 \pm 70$ & $214 \pm 78$ & -14 \\
\hline RT + PRO (-protein supplement) & $228 \pm 70$ & $210 \pm 92$ & -18 \\
\hline CON & $235 \pm 54$ & $262 \pm 65$ & +27 \\
\hline \multicolumn{4}{|l|}{ Fat Intake (g) } \\
\hline RT + PRO (total) & $88 \pm 17$ & $101 \pm 28$ & +13 \\
\hline RT + PRO (-protein supplement) & $88 \pm 17$ & $97 \pm 19$ & +9 \\
\hline $\mathrm{CON}$ & $112 \pm 34$ & $80 \pm 17$ & -32 \\
\hline
\end{tabular}

Values are mean (SE), $n=20(\mathrm{CON})$ and $n=19(\mathrm{RT}+\mathrm{PRO})$.

\subsubsection{Explaining Group Difference in Ad Libitum EI}

Prior to mediation analyses, a MANOVA was conducted to test for differences in change scores from baseline to week $12(\Delta$; calculated as Week 12 -baseline values $)$ in $a d$ libitum EI, postprandial subjective appetite, FM, FFM and RMR. This analysis revealed a multivariate effect of group, $F(5,33)=3.907, p=0.007, \eta^{2}=0.372$. Separate follow-up ANOVAs identified a significant group effect for $\Delta$ ad labium $\operatorname{EI}(F(1)=12.789, p=0.001$, $\left.\eta^{2}=0.257\right), \Delta$ FFM $\left(F(1)=10.568, p=0.002, \eta^{2}=0.222\right)$ and $\Delta$ postprandial subjective appetite $\left(F(1)=5.393, p=0.026, \eta^{2}=0.127\right)$, but not for $\Delta \mathrm{FM}$ or $\Delta \operatorname{RMR}(p>0.05)$. This supports the outcome of the linear mixed model which demonstrated that FFM and postprandial subjective appetite (AUC) were significantly higher in RT + PRO. Therefore, only $\triangle$ FFM and $\Delta$ postprandial subjective appetite were included as potential mediators in subsequent analysis. 
ANCOVAs were conducted with group as the independent variable, $\Delta$ ad libitum EI as the dependent variable, and with $\Delta$ FFM and $\Delta$ postprandial subjective appetite as covariates in separate ANCOVAs. When adjusting for $\triangle$ FFM, the effect of group on $\Delta$ ad libitum EI remained significant $(F(1)=6.052, p=0.034)$, but the effect was reduced $\left(\Delta \eta^{2}=0.138\right)$. As such, when adjusting for $\Delta \mathrm{FFM}$, the amount of variance in $\Delta$ ad libitum, EI attributed to the group (i.e., treatment) dropped from $25.7 \%$ to $11.9 \%$, indicating that $54 \%$ of the observed treatment effect on $\Delta$ ad libitum EI can be explained by $\Delta$ FFM (see Table 6). However, $\Delta$ postprandial subjective appetite did not satisfy the criteria to be considered as having a noteworthy contribution in accounting for the effect of the intervention on $\Delta$ ad libitum EI. This, therefore, suggests that $\Delta$ FFM partially mediated the effect of the intervention on $\Delta$ ad libitum EI. The relationship is further evidenced by a significant correlation between $\Delta$ ad libitum EI and $\Delta$ FFM $(r=0.527, p=0.001)$. However, a separate ANCOVA revealed $\Delta$ postprandial subjective appetite was not a significant covariate $(p=0.508)$ of the group effect on $\Delta$ ad libitum EI. Suggesting that $\Delta$ postprandial subjective appetite (proposed mediator) did not affect $\Delta$ ad libitum EI (dependent variable) when adjusting for group (independent variable). Therefore, $\Delta$ postprandial subjective appetite did not satisfy the criteria for mediation.

Table 6. Effect of covariates on group differences in ad libitum energy intake.

\begin{tabular}{ccccc}
\hline Analysis & $\mathbf{F}$ & $\eta^{2}$ & $\Delta \boldsymbol{\eta}^{2}$ & $p$-Value \\
\hline $\begin{array}{l}\text { One-way ANOVA } \\
\text { Group }\end{array}$ & $12.79 *$ & 0.257 & - & 0.01 \\
$\begin{array}{l}\text { One-way ANCOVA, group effect adjusting for } \\
\text { FFM }\end{array}$ & $4.85^{*}$ & 0.119 & 0.138 & 0.034 \\
\hline
\end{tabular}

FFM = Fat-free mass; $\eta^{2}=$ Eta squared; An Asterisk $\left(^{*}\right)$ represents a significant difference in change scores.

\subsection{Maximum Strength}

There was a significant group ${ }^{*}$ trial interaction (all $p<0.001$; See Table 7), group main effect (all $p \leq 0.030$ ) and effect for trial for all seven exercises (all $p<0.001$ ). Strength scores increased from baseline to Week 12 in RT + PRO; however, there was no change in CON.

Table 7. Maximum Strength scores from 5-RM, change from baseline to Week 12 in RT + PRO and CON.

\begin{tabular}{|c|c|c|c|c|}
\hline & Baseline & Week 12 & $\Delta$ from Baseline to Week $12(\mathrm{~kg})$ & Effect Size $(d)$ \\
\hline \multicolumn{5}{|l|}{ Seated Row } \\
\hline $\mathrm{RT}+\mathrm{PRO}$ & $37.2 \pm 12.3$ & $49.8 \pm 17.0$ & 12.6 & \multirow{2}{*}{1.05} \\
\hline $\mathrm{CON}$ & $33.5 \pm 14.1$ & $33.4 \pm 14.1$ & -0.1 & \\
\hline Leg Press & & & & \multirow[b]{3}{*}{0.78} \\
\hline $\mathrm{RT}+\mathrm{PRO}$ & $97.8 \pm 26.4$ & $151.9 \pm 29.2$ & 54.1 & \\
\hline $\mathrm{CON}$ & $95.1 \pm 38.8$ & $97.5 \pm 30.8$ & 0.0 & \\
\hline \multicolumn{5}{|l|}{ Chest Press } \\
\hline $\mathrm{RT}+\mathrm{PRO}$ & $33.5 \pm 18.1$ & $55.6 \pm 24.7$ & 22.1 & \multirow[b]{2}{*}{0.98} \\
\hline $\mathrm{CON}$ & $25.7 \pm 17.6$ & $28.7 \pm 17.9$ & 0.0 & \\
\hline Leg Curl & & & & \\
\hline $\mathrm{RT}+\mathrm{PRO}$ & $43.7 \pm 16.7$ & $70.9 \pm 19.7$ & 27.2 & \multirow{2}{*}{1.30} \\
\hline $\mathrm{CON}$ & $43.8 \pm 17.3$ & $40.8 \pm 17.3$ & -3.0 & \\
\hline \multicolumn{5}{|l|}{ Lat Pull Down } \\
\hline $\mathrm{RT}+\mathrm{PRO}$ & $35.2 \pm 12.8$ & $48.2 \pm 15.3$ & 13.0 & \multirow[b]{2}{*}{0.88} \\
\hline $\mathrm{CON}$ & $35.7 \pm 12.2$ & $32.7 \pm 12.2$ & 3.0 & \\
\hline \multicolumn{5}{|l|}{ Leg Extension } \\
\hline $\mathrm{RT}+\mathrm{PRO}$ & $45.0 \pm 16.8$ & $76.7 \pm 20.3$ & 31.7 & \multirow{2}{*}{1.16} \\
\hline $\mathrm{CON}$ & $43.4 \pm 18.3$ & $47.6 \pm 20.8$ & 4.2 & \\
\hline \multicolumn{5}{|l|}{ Shoulder Press } \\
\hline $\mathrm{RT}+\mathrm{PRO}$ & $21.4 \pm 14.6$ & $39.5 \pm 20.3$ & 18.1 & \multirow{2}{*}{0.80} \\
\hline $\mathrm{CON}$ & $15.9 \pm 10.1$ & $18.5 \pm 23.6$ & 2.6 & \\
\hline
\end{tabular}




\section{Discussion}

This study investigated the effects of increasing fat-free mass on resting metabolic rate, subjective appetite, appetite-related hormone concentrations and EI in older adults. The primary findings are that 12 -weeks of resistance training and protein supplementation led to a significant increase in FFM, ad-libitum EI, daily EI and postprandial subjective appetite perceptions in older adults. These changes were significant from week 6 to week 12 but not from baseline to week 6 of the intervention. However, these differences cannot be attributed to resting energy expenditure as resting metabolic rate was unaffected. Analysis did confirm that increases in EI and appetite were associated with the increase in FFM, with $54 \%$ of the change in ad libitum EI attributed to the increase in FFM alone. Fasted subjective appetite sensations, and appetite-related and metabolic hormones in both the fasted and postprandial states remained unchanged following the 12-week intervention. Maximum strength was also significantly improved in the RT + PRO.

The majority of studies conducted so far have explored the efficacy of exercise interventions from an obesity perspective, whereby reduction in weight and fat-mass in sedentary individuals are primary objectives [21]. Exercise intervention studies are either associated with negligible [70-72] or reduced [73,74] energy consumption after intervention completion despite significant reductions or a maintained fat-mass. Nevertheless, cross-sectional studies have demonstrated associations between FFM and EI [11,17,75]. Despite these inconsistent findings, the results of the present study observed a longitudinal association between changes in FFM and ad libitum EI. To our knowledge, this is the first study which supports the speculation that an increase in FFM alters the sensitivity to the appetite control system by augmenting the drive to eat. We can safely also speculate that an increase in FFM with weight gain may play a more important role in exerting feedback signals, which drive EI over fat mass since in our study only a modest and non-significant reduction in fat mass was observed on completion of the intervention. Increased ad libitum and daily EI were amplified concurrently to the significant increases in FFM $(+1.2 \mathrm{~kg})$ providing further support to this speculation. Nevertheless, the increase in daily EI should be interpreted with a degree of caution since the increase in habitual EI appears to be primarily due to the additional energy received through the supplement. Daily EI increased by an average $46 \mathrm{kcal}$ per day, thus the increased calorific intake did not surpass the calorific content of the whey protein supplement provided (+169 kcal per day). Protein has been shown to exert satiating effects and can often reduce overall EI [76] and is typically used as a weight loss strategy for overweight individuals. Whilst the current study indicates that participant's dietary EI irrespective of the protein supplements was reduced, overall EI was still heightened as a result of the intervention.

Our findings suggest that the tonic drive to eat is not underlined by resting energy expenditure given that resting metabolic rate remained unaltered following an increase in FFM. This is somewhat surprising considering that Campbell et al. [77] demonstrated a significant increase in resting metabolic rate following 12 weeks of resistance training alongside protein supplementation. Some differences in methodology may account for these discrepancies. For example, the participants attended three sessions per week creating a greater exercise stimulus, which results in a $1.4 \mathrm{~kg}$ gain in FFM. In addition, their participants were also untrained upon recruitment to the study. The assessment of resting metabolic rate was also undertaken in the postprandial state; therefore, the thermic effect of food would have been a confounding factor in their study. There is also some evidence to suggest that energy expenditure drives FFM-induced EI through specific lean tissue masses/organs, in particular, the skeletal muscle [78]. This hypothesis was formed based on the 'aminostatic' theory $[79,80]$ of appetite control and a 'protein-static' [81] control of food intake in which the lean tissue would drive the metabolic requirement to maintain its mass. Whilst appetite and EI did increase concurrently to the increase in FFM, the present study cannot attribute this to resting metabolic rate, which remained unchanged. Weise et al. [75] reported that FFM itself was associated with several brain regions involved in homeostatic appetite control following the tomographic measurement of regional cerebral blood flow 
in healthy adults. Therefore, it is speculated that the increase in appetite and EI in the present study could be a reflect centrally mediated mechanisms rather than resting energy expenditure per se.

Exercise training studies investigating appetite-related outcomes are crucial to determine the effectiveness of exercise and body composition for weight control. Whilst some research has explored the effect of 12-weeks aerobic exercise on appetite-related variables $[26,70-73,82,83]$, to date, only one study has explored the effects of 12 weeks supervised resistance training on appetite-related outcomes [84]. Resistance training showed no differences in hunger, fullness, active ghrelin, PP or PYY, on the other hand, leptin had significantly reduced. However, the extent to which this occurs in older adults from both an exercise and body composition perspective is yet to be unveiled. This is of particular importance due to the reductions in appetite, EI and muscle mass associated with ageing $[4,6]$. The results of the present study strongly suggest that ad libitum EI was increased as a result of the increases in FFM. This is supported by the non-significant increase in both ad libitum EI and FFM from baseline and week 6 of the intervention. This conflicts with Guelfi, Donges and Duffield [84] who demonstrated no differences in perceived hunger or fullness in the postprandial state following 12 weeks of resistance exercise. However, this study was conducted in previously sedentary overweight and obese middle-aged men and it is suggested that the coupling between EI and energy expenditure in this population is impaired [85]. The participants in the present study were at the lower end of overweight $\left(\mathrm{BMI}=25.7 \pm 3.6 \mathrm{~kg} \cdot \mathrm{m}^{-2}\right)$ and also previously active prior to the intervention, therefore the coupling between EI and energy expenditure are unlikely to be impaired. Nonetheless the data presented from the present study identify a role for FFM in appetite-related outcomes.

In addition, it has been proposed that fat mass and FFM may exert 'passive' and 'active' signals which drive appetite under different energy balance states [18]. The results from the present study indicate that the RT $+\mathrm{PRO}$ were in a positive energy balance given this is a requirement for increases in body weight and skeletal muscle mass [86]. However, it is proposed that during an energy deficit, FFM becomes an active driver of the tonic drive to eat to protect losses in lean tissues [78]. Research suggests that it is not perhaps resting metabolic rate itself that creates a tonic pull on EI at or close to EB, but the potential energy deficit that it can produce. It is apparent that even in a positive energy balance that FFM may act as an active signal to increase EI in older adults; however, this could not be attributed to changes in resting metabolic rate. The large gains seen in 5-RM strength concurrent to the significant increases in FFM indicate that the changes of FFM were likely driven be increases in skeletal muscle tissue. Therefore, increases in ad libitum EI may be driven actively by the skeletal muscle mass directly. More research is required about how EI changes under conditions of energy surfeit and deficit to confirm this.

The dose of exercise itself did not appear to substantially influence acute appetite responses. Exercise can raise resting values of energy expenditure several fold depending on the volume, mode and intensity [5]. It has been concluded that a single bout of exercise does affect the immediate post-exercise appetite response [23] including resistance exercise in older adults (unpublished data). However, after 9-16 days of repeated exercise research suggests a partial compensatory response begins to appear [24,25]. The present study observed no differences in subjective appetite sensations, EI and resting metabolic rate after 6 weeks of training whereby significant increases in FFM had not yet occurred. It is speculated that the energy expenditure from resistance exercise may not be sufficient in stimulating appetite compensatory responses.

The hormones measured in the present study were based on the results of our recent meta-analysis [6], which indicated that leptin, insulin, PYY and CCK were elevated in older adults compared to younger adults. The data of the present study demonstrated that the intervention did not affect circulating concentrations of both fasted and postprandial leptin and insulin compared to their baseline values. Many studies have focused on leptin and insulin in response to exercise training. The consensus of these studies suggest that leptin is reduced after both aerobic exercise, even when there were no changes in fat 
mass observed [87] nor resistance exercise where fat mass was significantly reduced [84], conflicting the findings of the current study. Whereas the results of insulin vary $[70,87]$. Discrepancies between the present study and Guelfi et al. [84] are likely due to the populations investigated. Many training studies typically recruit inactive individuals at baseline such as Guelfi and colleagues [84]; however, the present study was observed in older adults who were already active. The modulating effect of habitual activity on appetite-related hormones after an exercise training intervention is unknown. However, the differences observed in aerobic training studies are likely to originate from the differences in energy expenditure. A small collection of studies have shown increased acylated ghrelin, PYY, GLP-1 and PP following aerobic interventions [26,70,87]; however, similarly to current study the evidence after resistance training on appetite-related hormones excluding leptin are negligible [84]. Given that CCK and PYY is secreted in response to protein and also, exists in greater circulating concentrations in older adults when compared to young, this warrants future research.

Despite the novel findings in the present study, some notable limitations must be acknowledged. Firstly, in the present study participants were supervised for every resistance training session by a qualified trainer; however, this is unlikely in real-life scenarios due to cost implications, location and motivation. Compliance would likely pose an issue in a real-world setting if a resistance training programme was conducted individually. Additionally, resistance exercise requires good knowledge of anatomy and technique, which not all individuals possess, to minimise injury risk Future research should explore the effects of free-living or home-based interventions on muscle mass and appetite-related variables in older adults to determine effectiveness as well as efficacy. This study was also conducted in active and healthy older adults, who may not represent a true reflection of the older population on the whole. The effects may be different in older adults, who hold underlying comorbidities or diseases, since this may further implicate appetite regulation. Finally, the present study failed to assess total daily energy expenditure and habitual physical activity, due to limitations in free-living measures [88]; therefore, we can only speculate that exercise was not sufficient in stimulating compensatory changes in EI due to little differences in energy expenditure.

\section{Conclusions}

In conclusion, 12 weeks of resistance training and protein supplementation led to a significant increase in FFM, postprandial subjective appetite and ad libitum EI in older adults. There was a significant increase in ad libitum EI, which appeared to be mainly driven by the increase in FFM. In addition, the mechanisms which underpin increased postprandial subjective appetite and EI in older adults are unknown given that resting metabolic rate and appetite-related hormones concentrations remained unaltered. Based on the findings of the present study chronic resistance training and increased protein intake pose a successful strategy for enhancing FFM and EI, and breaking the vicious cycle between, appetite, EI, and muscle mass reductions in older adults.

Author Contributions: K.O.J., T.I. and A.H. undertook the study design, K.O.J., N.M., A.C., K.H. and L.L.O. undertook extensive data collection, K.O.J. undertook statistical analysis, A.H. and N.S. supported data analysis, K.O.J. produced the original draft manuscript, K.O.J., A.H., J.M. and T.I. edited and reviewed the manuscript. All authors have read and agreed to the published version of the manuscript.

Funding: This research received no external funding.

Institutional Review Board Statement: The study was conducted according to the guidelines of the Declaration of Helsinki, and approved by the Ethics Committee of Leeds Beckett University (Application Reference: 58906 and 12/03/2019).

Informed Consent Statement: Informed consent was obtained from all subjects involved in the study.

Data Availability Statement: The data presented in this study are available on request from the corresponding author. 
Acknowledgments: The authors would like to acknowledge Jennifer Peel for assistance with data collection.

Conflicts of Interest: The authors declare no conflict of interest.

\section{References}

1. Morley, J.E.; Silver, A.J. Anorexia in the elderly. Neurobiol. Aging 1988, 9, 9-16. [CrossRef]

2. Roberts, S.B.; Rosenberg, I. Nutrition and Aging: Changes in the Regulation of Energy Metabolism with Aging. Physiol. Rev. 2006, 86, 651-667. [CrossRef]

3. Leij-Halfwerk, S.; Verwijs, M.H.; van Houdt, S.; Borkent, J.W.; Guaitoli, P.; Pelgrim, T.; Heymans, M.W.; Power, L.; Visser, M.; Corish, C.A. Prevalence of protein-energy malnutrition risk in European older adults in community, residential and hospital settings, according to 22 malnutrition screening tools validated for use in adults $\geq 65$ years: A systematic review and meta-analysis. Maturitas 2019, 126, 80-89. [CrossRef]

4. Rolland, Y.; Van Kan, G.A.; Gillette-Guyonnet, S.; Vellas, B. Cachexia versus sarcopenia. Curr. Opin. Clin. Nutr. Metab. Care 2011, 14, 15-21. [CrossRef]

5. $\quad$ Blundell, J.E.; Caudwell, P.; Gibbons, C.; Hopkins, M.; Naslund, E.; King, N.; Finlayson, G. Role of resting metabolic rate and energy expenditure in hunger and appetite control: A new formulation. Dis. Model. Mech. 2012, 5, 608-613. [CrossRef]

6. Johnson, K.O.; Shannon, O.M.; Matu, J.; Holliday, A.; Ispoglou, T.; Deighton, K.; Johnson, K. Differences in circulating appetiterelated hormone concentrations between younger and older adults: A systematic review and meta-analysis. Aging Clin. Exp. Res. 2020, 32, 1233-1244. [CrossRef]

7. Johnstone, A.M.; Murison, S.D.; Duncan, J.S.; Rance, K.A.; Speakman, J.R. Factors influencing variation in basal metabolic rate include fat-free mass, fat mass, age, and circulating thyroxine but not sex, circulating leptin, or triiodothyronine. Am. J. Clin. Nutr. 2005, 82, 941-948. [CrossRef]

8. Johnstone, A.M.; Rance, K.A.; Murison, S.D.; Duncan, J.S.; Speakman, J.R. Additional anthropometric measures may improve the predictability of basal metabolic rate in adult subjects. Eur. J. Clin. Nutr. 2006, 60, 1437-1444. [CrossRef] [PubMed]

9. Ravussin, E.; Burnand, B.; Schutz, Y.; Jéquier, E. Twenty-four-hour energy expenditure and resting metabolic rate in obese, moderately obese, and control subjects. Am. J. Clin. Nutr. 1982, 35, 566-573. [CrossRef] [PubMed]

10. Keys, A.; Taylor, H.L.; Grande, F. Basal metabolism and age of adult man. Metabolism 1973, 22, 579-587. [CrossRef]

11. Caudwell, P.; Finlayson, G.; Gibbons, C.; Hopkins, M.J.D.; King, N.; Näslund, E.; Blundell, J.E. Resting metabolic rate is associated with hunger, self-determined meal size, and daily energy intake and may represent a marker for appetite. Am. J. Clin. Nutr. 2012, 97, 7-14. [CrossRef] [PubMed]

12. Westerterp-Plantenga, M.S.; Goris, A.H.C.; Meijer, E.P.; Westerterp, K.R. Habitual meal frequency in relation to resting and activity-induced energy expenditure in human subjects: The role of fat-free mass. Br. J. Nutr. 2003, 90, 643-649. [CrossRef] [PubMed]

13. Weise, C.M.; Hohenadel, M.G.; Krakoff, J.; Votruba, S.B. Body composition and energy expenditure predict ad-libitum food and macronutrient intake in humans. Int. J. Obes. 2013, 38, 243-251. [CrossRef]

14. Blundell, J.E.; Caudwell, P.; Gibbons, C.; Hopkins, M.; Näslund, E.; King, N.A.; Finlayson, G. Body composition and appetite: Fat-free mass (but not fat mass or BMI) is positively associated with self-determined meal size and daily energy intake in humans. Br. J. Nutr. 2012, 107, 445-449. [CrossRef] [PubMed]

15. Cugini, P.; Salandri, A.; Cilli, M.; Ceccotti, P.; Di Marzo, A.; Rodio, A.; Fontana, S.; Pellegrino, A.M.; De Francesco, G.P.; Coda, S.; et al. Daily hunger sensation and body compartments: II. Their relationships in obese patients. Eat. Weight. Disord. Stud. Anorexia Bulim. Obes. 1999, 4, 81-88. [CrossRef] [PubMed]

16. Lissner, L.; Habicht, J.P.; Strupp, B.J.; Levitsky, D.A.; Haas, J.D.; Roe, D.A. Body composition and energy intake: Do overweight women overeat and underreport? Am. J. Clin. Nutr. 1989, 49, 320-325. [CrossRef] [PubMed]

17. Hopkins, M.; Finlayson, G.; Duarte, C.; Whybrow, S.; Ritz, P.; Horgan, G.W.; Blundell, J.E.; Stubbs, R.J. Modelling the associations between fat-free mass, resting metabolic rate and energy intake in the context of total energy balance. Int. J. Obes. 2015, 40, 312-318. [CrossRef]

18. Stubbs, R.J.; Hopkins, M.; Finlayson, G.S.; Duarte, C.; Gibbons, C.; Blundell, J.E. Potential effects of fat mass and fat-free mass on energy intake in different states of energy balance. Eur. J. Clin. Nutr. 2018, 72, 698-709. [CrossRef]

19. Blundell, J.E.; Gibbons, C.; Beaulieu, K.; Casanova, N.; Duarte, C.; Finlayson, G.; Stubbs, R.J.; Hopkins, M. The drive to eat in homo sapiens: Energy expenditure drives energy intake. Physiol. Behav. 2020, 219, 112846. [CrossRef]

20. Blundell, J.E.; Gibbons, C.; Caudwell, P.; Finlayson, G.; Hopkins, M. Appetite control and energy balance: Impact of exercise. Obes. Rev. 2015, 16, 67-76. [CrossRef]

21. Dorling, J.L.; Broom, D.R.; Burns, S.F.; Clayton, D.J.; Deighton, K.; James, L.; King, J.A.; Miyashita, M.; Thackray, A.E.; Batterham, R.L.; et al. Acute and Chronic Effects of Exercise on Appetite, Energy Intake, and Appetite-Related Hormones: The Modulating Effect of Adiposity, Sex, and Habitual Physical Activity. Nutrients 2018, 10, 1140. [CrossRef] [PubMed]

22. King, N.A.; Burley, V.J.; Blundell, J.E. Exercise-induced suppression of appetite: Effects on food intake and implications for energy balance. Eur. J. Clin. Nutr. 1994, 48, 715-724. [PubMed]

23. Deighton, K.; Stensel, D.J. Creating an acute energy deficit without stimulating compensatory increases in appetite: Is there an optimal exercise protocol? Proc. Nutr. Soc. 2014, 73, 352-358. [CrossRef] [PubMed] 
24. Stubbs, R.J.; Hughes, D.A.; Johnstone, A.M.; Horgan, G.W.; King, N.; Blundell, J.E. A decrease in physical activity affects appetite, energy, and nutrient balance in lean men feeding ad libitum. Am. J. Clin. Nutr. 2004, 79, 62-69. [CrossRef] [PubMed]

25. Stubbs, R.J.; Hughes, D.A.; Johnstone, A.M.; Whybrow, S.; Horgan, G.W.; King, N.; Blundell, J. Rate and extent of compensatory changes in energy intake and expenditure in response to altered exercise and diet composition in humans. Am. J. Physiol. Integr. Comp. Physiol. 2004, 286, R350-R358. [CrossRef] [PubMed]

26. Martins, C.; Kulseng, B.; King, N.A.; Holst, J.J.; Blundell, J.E. The Effects of Exercise-Induced Weight Loss on Appetite-Related Peptides and Motivation to Eat. J. Clin. Endocrinol. Metab. 2010, 95, 1609-1616. [CrossRef] [PubMed]

27. Tang, J.E.; Phillips, S.M. Maximizing muscle protein anabolism: The role of protein quality. Curr. Opin. Clin. Nutr. Metab. Care 2009, 12, 66-71. [CrossRef]

28. Tieland, M.; Dirks, M.L.; Van Der Zwaluw, N.; Verdijk, L.B.; Van De Rest, O.; De Groot, L.C.; Van Loon, L.J. Protein Supplementation Increases Muscle Mass Gain During Prolonged Resistance-Type Exercise Training in Frail Elderly People: A Randomized, Double-Blind, Placebo-Controlled Trial. J. Am. Med Dir. Assoc. 2012, 13, 713-719. [CrossRef]

29. Jeor, S.T.S.; Brunner, R.L.; Harrington, M.E.; Scott, B.J.; Daugherty, S.A.; Cutter, G.R.; Brownell, K.D.; Dyer, A.R.; Foreyt, J.P. A Classification System to Evaluate Weight Maintainers, Gainers, and Losers. J. Am. Diet. Assoc. 1997, 97, 481-488. [CrossRef]

30. Goran, M.I. Energy Metabolism and Obesity. Med Clin. North Am. 2000, 84, 347-362. [CrossRef]

31. Ravussin, E.; Lillioja, S.; Anderson, T.E.; Christin, L.; Bogardus, C. Determinants of 24-hour energy expenditure in man. Methods and results using a respiratory chamber. J. Clin. Investig. 1986, 78, 1568-1578. [CrossRef]

32. Costanza, M.C. Matching. Prev. Med. 1995, 24, 425-433. [CrossRef] [PubMed]

33. Rothman, K.J.; Greenland, S.; Lash, T.L. Modern Epidemiology; Lippincott Williams \& Wilkins: Philadelphia, PA, USA, 2008.

34. Willoughby, D.S. Resistance training in the older adult. In ACSM Current Comment; American College of Sports Medicine: Indiana, IN, USA, 2015.

35. Mayhew, J.L.; Ball, T.E.; Arnold, M.D.; Bowen, J.C. Relative muscular endurance performance as a predictor of bench press strength in college men and women. J. Strength Cond. Res. 1992, 6, 200-206.

36. Bauer, J.; Biolo, G.; Cederholm, T.; Cesari, M.; Cruz-Jentoft, A.J.; Morley, J.E.; Phillips, S.; Sieber, C.; Stehle, P.; Teta, D.; et al. Evidence-Based Recommendations for Optimal Dietary Protein Intake in Older People: A Position Paper From the PROT-AGE Study Group. J. Am. Med Dir. Assoc. 2013, 14, 542-559. [CrossRef] [PubMed]

37. Symons, T.B.; Sheffield-Moore, M.; Wolfe, R.R.; Paddon-Jones, D. Moderating the portion size of a protein-rich meal improves anabolic efficiency in young and elderly. J. Am. Diet. Assoc. 2009, 109, 1582. [CrossRef] [PubMed]

38. Compher, C.; Frankenfield, D.; Keim, N.; Roth-Yousey, L.; Evidence Analysis Working Group. Best Practice Methods to Apply to Measurement of Resting Metabolic Rate in Adults: A Systematic Review. J. Am. Diet. Assoc. 2006, 106, 881-903. [CrossRef]

39. Branson, R.; Johannigman, J.A. The Measurement of Energy Expenditure. Nutr. Clin. Pr. 2004, 19, 622-636. [CrossRef]

40. Henry, C.J.K. Basal metabolic rate studies in humans: Measurement and development of new equations. Public Heal. Nutr. 2005, 8, 1133-1152. [CrossRef]

41. Weir, J.B.D.V. New methods for calculating metabolic rate with special reference to protein metabolism. J. Physiol. 1949, 109, 1-9. [CrossRef]

42. Higgins, P.B.; Fields, D.A.; Hunter, G.R.; Gower, B.A. Effect of Scalp and Facial Hair on Air Displacement Plethysmography Estimates of Percentage of Body Fat. Obesity 2001, 9, 326-330. [CrossRef] [PubMed]

43. McCrory, M.A.; Gomez, T.D.; Bernauer, E.; Mole, P. Evaluation of a new air displacement plethysmograph for measuring human body composition. Med. Sci. Sports Exerc. 1995, 27, 1686-1691. [CrossRef] [PubMed]

44. Crapo, R.O.; Morris, A.H.; Clayton, P.D.; Nixon, C.R. Lung volumes in healthy nonsmoking adults. Bull. Eur. Physiopathol. Respir. 1982, 18, 419-425. [PubMed]

45. Dempster, P.; Aitkens, S. A new air displacement method for the determination of human body composition. Med. Sci. Sports Exerc. 1995, 27, 1692-1697. [CrossRef]

46. Siri, W.E. Body composition from fluid spaces and density: Analysis of methods. 1961. Nutrition 1993, 9, 480-491.

47. Gibney, M.J.; Lanham-New, S.A.; Cassidy, A.; Vorster, H.H. Introduction to Human Nutrition, 2nd ed.; John Wiley \& Sons Ltd. Publication: Hoboken, NJ, USA, 2009.

48. Gaal, S.; Kerr, M.A.; Ward, M.; McNulty, H.; Livingstone, M.B.E. Breakfast Consumption in the UK: Patterns, Nutrient Intake and Diet Quality. A Study from the International Breakfast Research Initiative Group. Nutrients 2018, 10, 999. [CrossRef]

49. Blundell, J.; De Graaf, C.; Hulshof, T.; Jebb, S.; Livingstone, B.; Lluch, A.; Mela, D.; Salah, S.; Schuring, E.; Van Der Knaap, H.; et al. Appetite control: Methodological aspects of the evaluation of foods. Obes. Rev. 2010, 11, 251-270. [CrossRef]

50. Stubbs, R.J.; Hughes, D.A.; Johnstone, A.M.; Rowley, E.; Reid, C.; Elia, M.; Stratton, R.; Delargy, H.; King, N.; Blundell, J.E. The use of visual analogue scales to assess motivation to eat in human subjects: A review of their reliability and validity with an evaluation of new hand-held computerized systems for temporal tracking of appetite ratings. Br. J. Nutr. 2000, 84, 405-415. [CrossRef]

51. Hill, A.J.; Blundell, J.E. Nutrients and behaviour: Research strategies for the investigation of taste characteristics, food preferences, hunger sensations and eating patterns in man. J. Psychiatr. Res. 1982, 17, 203-212. [CrossRef]

52. Date, Y. The vagus nerve and ghrelin function. In Metabotropic Glutamate Receptors; Springer Science and Business Media LLC: Berlin, Germany, 2014; Volume 25, pp. 53-61. 
53. Fawcett, J.K.; Wynn, V. Effects of Posture on Plasma Volume and Some Blood Constituents. J. Clin. Pathol. 1960, 13, 304-310. [CrossRef]

54. Public Health England. Government Dietary Recommendations- Government Recommendations for Energy and Nutrients for Males and Females Aged 1-18 Years and 19+ Years; Public Health England: London, UK, 2016.

55. Deighton, K.; Frampton, J.; Gonzalez, J.T. Test-meal palatability is associated with overconsumption but better represents preceding changes in appetite in non-obese males. Br. J. Nutr. 2016, 116, 935-943. [CrossRef] [PubMed]

56. Taylor, J.D.; Fletcher, J.P. Reliability of the 8-repetition maximum test in men and wom en. J. Sci. Med. Sport 2012, 15, 69-73. [CrossRef] [PubMed]

57. Gail, S.; Rodefeld, S.; Künzell, S. Reproducibility of a 5-repetition maximum strength test in older adults. Isokinet. Exerc. Sci. 2015, 23, 291-295. [CrossRef]

58. Haff, G.; Triplett, N. Essentials of Strength Training and Conditioning, 4th ed.; Human Kinetics: Champaign, IL, USA, 2016.

59. Schwanbeck, S.; Chilibeck, P.D.; Binsted, G. A Comparison of Free Weight Squat to Smith Machine Squat Using Electromyography. J. Strength Cond. Res. 2009, 23, 2588-2591. [CrossRef]

60. Wood, T.M.; Maddalozzo, G.F.; Harter, R.A. Accuracy of Seven Equations for Predicting 1-RM Performance of Apparently Healthy, Sedentary Older Adults. Meas. Phys. Educ. Exerc. Sci. 2002, 6, 67-94. [CrossRef]

61. Torres, V.; Medina, Y.; Rodríguez, Y.; Sardiñas, Y.; Herrera, M.; Rodríguez, R. Application of the linear mixed and generalized mixed model as alternatives for analysis in experiments with repeated measures. Cuban. J. Agric. Sci. 2019, 53, 7-12.

62. Cnaan, A.; Laird, N.M.; Slasor, P. Using the general linear mixed model to analyse unbalanced repeated measures and longitudinal data. Stat. Med. 1997, 16, 2349-2380. [CrossRef]

63. Baayen, R.H.; Davidson, D.; Bates, D. Mixed-effects modeling with crossed random effects for subjects and items. J. Mem. Lang. 2008, 59, 390-412. [CrossRef]

64. Harrison, X.A.; Donaldson, L.; Correa-Cano, M.E.; Evans, J.C.; Fisher, D.N.; Goodwin, C.E.; Robinson, B.S.; Hodgson, D.; Inger, R. A brief introduction to mixed effects modelling and multi-model inference in ecology. PeerJ 2018, 6, e4794. [CrossRef]

65. Hopkins, W. How to interpret changes in an athletic performance test (Online). Sport science 2004, 8, 1-7.

66. Hill, R.J.; Davies, P.S.W. The validity of self-reported energy intake as determined using the doubly labelled water technique. Br. J. Nutr. 2001, 85, 415-430. [CrossRef] [PubMed]

67. Cohen, J.; Cohen, P.; West, S.G.; Aiken, L.S. Applied Multiple Regression/Correlation Analysis for the Behavioral Sciences; Routledge: Abingdon, UK, 2013.

68. Tabachnick, B.G.; Fidell, L.S.; Ullman, J.B. Using Multivariate Statistics; Pearson: Boston, MA, USA, 2007 ; Volume 5.

69. Alajmi, N.; Deighton, K.; King, J.A.; Reischak-Oliveira, A.; Wasse, L.K.; Jones, J.; Batterham, R.L.; Stensel, D.J. Appetite and Energy Intake Responses to Acute Energy Deficits in Females versus Males. Med. Sci. Sports Exerc. 2016, 48, 412-420. [CrossRef] [PubMed]

70. Rosenkilde, M.; Reichkendler, M.H.; Auerbach, P.; Toräng, S.; Gram, A.S.; Ploug, T.; Holst, J.J.; Sjödin, A.; Stallknecht, B. Appetite regulation in overweight, sedentary men after different amounts of endurance exercise: A randomized controlled trial. J. Appl. Physiol. 2013, 115, 1599-1609. [CrossRef] [PubMed]

71. Bryant, E.J.; Caudwell, P.; Hopkins, M.E.; King, N.A.; Blundell, J.E. Psycho-markers of weight loss. The roles of TFEQ Disinhibition and Restraint in exercise-induced weight management. Appetite 2012, 58, 234-241. [CrossRef] [PubMed]

72. Martins, C.; Kulseng, B.; Rehfeld, J.F.; King, N.A.; Blundell, J.E. Effect of Chronic Exercise on Appetite Control in Overweight and Obese Individuals. Med. Sci. Sports Exerc. 2013, 45, 805-812. [CrossRef] [PubMed]

73. Cornier, M.-A.; Melanson, E.L.; Salzberg, A.K.; Bechtell, J.L.; Tregellas, J.R. The effects of exercise on the neuronal response to food cues. Physiol. Behav. 2012, 105, 1028-1034. [CrossRef]

74. Martins, C.; Truby, H.; Morgan, L.M. Short-term appetite control in response to a 6-week exercise programme in sedentary volunteers. Br. J. Nutr. 2007, 98, 834-842. [CrossRef]

75. Weise, C.M.; Thiyyagura, P.; Reiman, E.M.; Chen, K.; Krakoff, J. A potential role for the midbrain in integrating fat-free mass determined energy needs: An H215O PET study. Hum. Brain Mapp. 2015, 36, 2406-2415. [CrossRef]

76. Poppitt, S.; McCormack, D.; Buffenstein, R. Short-term effects of macronutrient preloads on appetite and energy intake in lean women. Physiol. Behav. 1998, 64, 279-285. [CrossRef]

77. Campbell, W.W.; Crim, M.C.; Young, V.R.; Evans, W.J. Increased energy requirements and changes in body composition with resistance training in older adults. Am. J. Clin. Nutr. 1994, 60, 167-175. [CrossRef]

78. Dulloo, A.G.; Jacquet, J.; Miles-Chan, J.L.; Schutz, Y. Passive and active roles of fat-free mass in the control of energy intake and body composition regulation. Eur. J. Clin. Nutr. 2016, 71, 353-357. [CrossRef] [PubMed]

79. Mellinkoff, S.M.; Frankland, M.; Boyle, D.; Greipel, M. Relationship Between Serum Amino Acid Concentration and Fluctuations in Appetite. J. Appl. Physiol. 1956, 8, 535-538. [CrossRef] [PubMed]

80. Bray, G.A. Amino acids, protein, and body weight. Obes. Res. 1997, 5, 373-376. [CrossRef] [PubMed]

81. Millward, D.J. A Protein-Stat Mechanism for Regulation of Growth and Maintenance of the Lean Body Mass. Nutr. Res. Rev. 1995, 8, 93-120. [CrossRef]

82. King, N.A.; Caudwell, P.P.; Hopkins, M.; Stubbs, J.R.; Naslund, E.; Blundell, J.E. Dual-process action of exercise on appetite control: Increase in orexigenic drive but improvement in meal-induced satiety. Am. J. Clin. Nutr. 2009, 90, 921-927. [CrossRef] 
83. Caudwell, P.; Gibbons, C.; Hopkins, M.; King, N.; Finlayson, G.; Blundell, J. No Sex Difference in Body Fat in Response to Supervised and Measured Exercise. Med. Sci. Sports Exerc. 2013, 45, 351-358. [CrossRef]

84. Guelfi, K.J.; Donges, C.E.; Duffield, R. Beneficial effects of 12 weeks of aerobic compared with resistance exercise training on perceived appetite in previously sedentary overweight and obese men. Metabolism 2013, 62, 235-243. [CrossRef]

85. Beaulieu, K.; Hopkins, M.; Blundell, J.; Finlayson, G. Homeostatic and non-homeostatic appetite control along the spectrum of physical activity levels: An updated perspective. Physiol. Behav. 2018, 192, 23-29. [CrossRef]

86. Lambert, C.P.; Frank, L.L.; Evans, W.J. Macronutrient Considerations for the Sport of Bodybuilding. Sports Med. 2004, 34, 317-327. [CrossRef]

87. Morishima, T.; Kurihara, T.; Hamaoka, T.; Goto, K. Whole body, regional fat accumulation, and appetite-related hormonal response after hypoxic training. Clin. Physiol. Funct. Imaging 2014, 34, 90-97. [CrossRef]

88. O'Driscoll, R.; Turicchi, J.; Beaulieu, K.; Scott, S.; Matu, J.; Deighton, K.; Finlayson, G.; Stubbs, J. How well do activity monitors estimate energy expenditure? A systematic review and meta-analysis of the validity of current technologies. Br. J. Sports Med. 2018, 54, 332-340. [CrossRef] [PubMed] 